\title{
Small Radioisotope Power System Testing at NASA Glenn Research Center
}

\author{
Gina Dugala \\ Glenn Research Center, Cleveland, Ohio \\ Mark Bell \\ Vantage Partners, LLC, Brook Park, Ohio \\ Salvatore Oriti \\ Glenn Research Center, Cleveland, Ohio \\ Martin Fraeman, David Frankford, and Dennis Duven \\ The Johns Hopkins University, Applied Physics Laboratory, Laurel, Maryland
}




\section{NASA STI Program ... in Profile}

Since its founding, NASA has been dedicated to the advancement of aeronautics and space science. The NASA Scientific and Technical Information (STI) program plays a key part in helping NASA maintain this important role.

The NASA STI Program operates under the auspices of the Agency Chief Information Officer. It collects, organizes, provides for archiving, and disseminates NASA's STI. The NASA STI program provides access to the NASA Aeronautics and Space Database and its public interface, the NASA Technical Reports Server, thus providing one of the largest collections of aeronautical and space science STI in the world. Results are published in both non-NASA channels and by NASA in the NASA STI Report Series, which includes the following report types:

- TECHNICAL PUBLICATION. Reports of completed research or a major significant phase of research that present the results of NASA programs and include extensive data or theoretical analysis. Includes compilations of significant scientific and technical data and information deemed to be of continuing reference value. NASA counterpart of peer-reviewed formal professional papers but has less stringent limitations on manuscript length and extent of graphic presentations.

- TECHNICAL MEMORANDUM. Scientific and technical findings that are preliminary or of specialized interest, e.g., quick release reports, working papers, and bibliographies that contain minimal annotation. Does not contain extensive analysis.

- CONTRACTOR REPORT. Scientific and technical findings by NASA-sponsored contractors and grantees.
- CONFERENCE PUBLICATION. Collected papers from scientific and technical conferences, symposia, seminars, or other meetings sponsored or cosponsored by NASA.

- SPECIAL PUBLICATION. Scientific, technical, or historical information from NASA programs, projects, and missions, often concerned with subjects having substantial public interest.

- TECHNICAL TRANSLATION. Englishlanguage translations of foreign scientific and technical material pertinent to NASA's mission.

Specialized services also include creating custom thesauri, building customized databases, organizing and publishing research results.

For more information about the NASA STI program, see the following:

- Access the NASA STI program home page at http://www.sti.nasa.gov

- E-mail your question to help@sti.nasa.gov

- Fax your question to the NASA STI Information Desk at 443-757-5803

- Phone the NASA STI Information Desk at 443-757-5802

- Write to: STI Information Desk NASA Center for AeroSpace Information 7115 Standard Drive Hanover, MD 21076-1320 


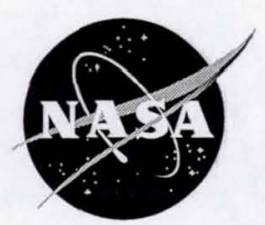

\title{
Small Radioisotope Power System Testing at NASA Glenn Research Center
}

\author{
Gina Dugala \\ Glenn Research Center, Cleveland, Ohio \\ Mark Bell \\ Vantage Partners, LLC, Brook Park, Ohio \\ Salvatore Oriti \\ Glenn Research Center, Cleveland, Ohio \\ Martin Fraeman, David Frankford, and Dennis Duven \\ The Johns Hopkins University, Applied Physics Laboratory, Laurel, Maryland
}

Prepared for the

11th International Energy Conversion Engineering Conference (IECEC)

sponsored by the American Institute of Aeronautics and Astronautics

San Jose, California, July 14-17, 2013

National Aeronautics and

Space Administration

Glenn Research Center

Cleveland, Ohio 44135 


\section{Acknowledgments}

This work is funded through the NASA Science Mission Directorate. The authors wish to acknowledge personnel at NASA Glenn Research Center, The Johns Hopkins University Applied Physics Laboratory (JHU/APL), and Sunpower, Inc., for their support and contributions to this project.

Level of Review: This material has been technically reviewed by technical management.

Available from

NASA Center for Aerospace Information 7115 Standard Drive

Hanover, MD 21076-1320
National Technical Information Service 5301 Shawnee Road Alexandria, VA 22312

Available electronically at http://www.sti.nasa.gov 


\title{
Small Radioisotope Power System Testing at NASA Glenn Research Center
}

\author{
Gina Dugala \\ National Aeronautics and Space Administration \\ Glenn Research Center \\ Cleveland, Ohio 44135 \\ Mark Bell \\ Vantage Partners, LLC \\ Brook Park, Ohio 44142 \\ Salvatore Oriti \\ National Aeronautics and Space Administration \\ Glenn Research Center \\ Cleveland, Ohio 44135 \\ Martin Fraeman, David Frankford, and Dennis Duven \\ The Johns Hopkins University \\ Applied Physics Laboratory \\ Laurel, Maryland 20723
}

\begin{abstract}
In April 2009, NASA Glenn Research Center formed an integrated product team (IPT) to develop a Small Radioisotope Power System (SRPS) utilizing a single Advanced Stirling Convertor (ASC) with a passive balancer. A single ASC produces approximately $80 \mathrm{~W}_{\mathrm{e}}$ making this system advantageous for small distributed lunar science stations. The IPT consists of Sunpower, Inc., to provide the single ASC with a passive balancer, The Johns Hopkins University Applied Physics Laboratory (JHU/APL) to design an engineering model Single Convertor Controller (SCC) for an ASC with a passive balancer, and NASA Glenn to provide technical support to these tasks and to develop a simulated lunar lander test stand. The single ASC with a passive balancer, simulated lunar test stand, and SCC were delivered to Glenn and were tested as a system. The testing sequence at Glenn included SCC fault tolerance, integration, electromagnetic interference (EMI), vibration, and extended operation testing. The SCC fault tolerance test characterized the SCC's ability to handle various fault conditions, including high or low bus power consumptions, total open load or short circuit, and replacing a failed SCC card while the backup maintains control of the ASC. The integrated test characterized the behavior of the system across a range of operating conditions, including variations in cold-end temperature and piston amplitude, including the emitted vibration to both the sensors on the lunar lander and the lunar surface. The EMI test characterized the alternating current (AC) and direct current (DC) magnetic and electric fields emitted by the single ASC. The vibration test confirms the SCC's ability to control the single ASC during launch. The extended operation test allows data to be collected over a period of thousands of hours to obtain long-term performance data of the ASC with a passive balancer and the SCC. This paper will discuss the results of each these tests.
\end{abstract}

\section{Nomenclature}

AC alternating current

APS ASC piston sensor 


$\begin{array}{ll}\text { ASC } & \text { Advanced Stirling Convertor } \\ \text { ASC-E2 } & \text { second-generation-level Advanced Stirling Convertor } \\ \text { ASC-L } & \text { Lunar-Derived Advanced Stirling Convertor } \\ \text { ASRG } & \text { Advanced Stirling Radioisotope Generator } \\ \text { CSAF } & \text { cold-side adapter flange } \\ \text { DAQ } & \text { data acquisition } \\ \text { DoE } & \text { Department of Energy } \\ \text { DC } & \text { direct current } \\ \text { EM } & \text { engineering model } \\ \text { EMF } & \text { electromotive force } \\ \text { EMI } & \text { electromagnetic interference } \\ \text { FMEA } & \text { Failure Mode and Effects Analysis } \\ \text { FPC } & \text { failsafe protection circuit } \\ \text { FPGA } & \text { field programmable gate array } \\ \text { ILN } & \text { International Lunar Network } \\ \text { IPS } & \text { integrated product team } \\ \text { JHU/APL } & \text { Johns Hopkins University/Applied Physics Laboratory } \\ \text { LED } & \text { light-emitting diode } \\ \text { MEDA } & \text { Macintyre Electronic Design Associates } \\ \text { PID } & \text { proportional integral derivative } \\ \text { PV } & \text { pressure vessel } \\ \text { PWM } & \text { pulse width modulation } \\ \text { RMS } & \text { root mean square } \\ \text { SCC } & \text { Single Convertor Controller } \\ \text { SRL } & \text { Stirling Research Laboratory } \\ \text { SRPS } & \text { Small Radioisotope Power System } \\ \text { UPS } & \text { uninterruptible power supply } \\ \text { We } & \text { Watt electric } \\ & \end{array}$

\subsection{Introduction}

NASA Glenn Research Center is the lead NASA center for the development of the Advanced Stirling Convertor (ASC) for use in space. In April 2009, NASA Glenn formed an integrated product team (IPT) to develop a Small Radioisotope Power System (SRPS) utilizing a single ASC with a passive balancer for possible use by the International Lunar Network (ILN) program. At that time, the ILN program was studying the feasibility of implementing a multiple-node seismometer network to investigate the internal lunar structure. A single ASC produces approximately $80 \mathrm{~W}_{\mathrm{e}}$ and could potentially supply sufficient power for that application. The IPT consists of Sunpower, Inc., to provide an ASC with a balancer, The Johns Hopkins University Applied Physics Laboratory (JHU/APL) to design an engineering model (EM) Single Convertor Controller (SCC) for the single ASC with a balancer, and NASA Glenn to provide technical support to these tasks and to develop a simulated lunar lander test stand.

The requirements for the SRPS differ from those driving the design and implementation of the Department of Energy (DoE) and NASA's Advanced Radioisotope Stirling Generator (ASRG). The main difference is that the required output power is modest and could be supplied by a single ASC-type Stirling convertor using half as much radioisotope fuel. Other differences from the ASRG include higher coldside adapter temperature and the need to control one rather than two convertor power sources. 
The Lunar-Derived Advanced Stirling Convertor (ASC-L) and SCC were developed to address these differences. The ASC alternator magnet was modified to operate at higher temperatures and a passive balancer was added to reduce vibration forces exerted by the convertor on the host. A fault-tolerant electronic controller, the SCC, for a single ASC was also developed. The controller included provisions to fully protect the convertor from single point failures in the controller and spacecraft. The controller also contains functionality to fully protect the spacecraft from single point failures in the convertor and controller. In either case, after a failure is corrected, the SCC design supports continuation of the mission. A lunar lander simulated test stand was developed to characterize the vibration produced by an ASC and understand its impact on a lunar lander. Several tests were performed on the system and individual components in order to reduce the risks associated with developing a small radioisotope power source for space (primarily lunar surface) applications based on using a single Stirling convertor. The results to these tests are presented in this paper.

\subsection{Small Radioisotope Power System (SRPS) Components}

\subsection{Lunar-Derived Advanced Stirling Convertor (ASC-L) With Passive Balancer}

The ASC-E2 is a second generation of the engineering-level advanced Stirling convertor development by Sunpower, Inc. As a technology effort, the ASC-E2 design was evaluated to extend the current capabilities by investigating the adaptation of the technology to environments demanding higher rejection temperatures and higher alternator temperatures. Sunpower, Inc., built an ASC-L to demonstrate these capabilities. The ASC-L design is based on an ASC-E2 with limited changes and is intended for single-convertor configuration. The performance characteristics and temperature limits of the alternator were evaluated.

The ASC-L differs from an ASC-E2 in four ways. First, higher temperature magnets were installed for an expanded cold-side adapter flange (CSAF) temperature range of 47 to $147^{\circ} \mathrm{C}$ and a pressure vessel (PV) temperature range of 55 to $155^{\circ} \mathrm{C}$. In contrast, the ASC-E2s operated at a CSAF temperature range of 17 to $125^{\circ} \mathrm{C}$ and a $\mathrm{PV}$ temperature range of 21 to $132^{\circ} \mathrm{C}$. The rejection temperature range is based on simulations of expected lunar day/night temperatures. PV temperatures were assumed to be approximately $8{ }^{\circ} \mathrm{C}$ higher than the rejection temperature based on analysis performed by Sunpower, Inc. The ASC-L will operate at high-rejection temperatures for performance mapping only. Nominal operation is $850{ }^{\circ} \mathrm{C}$ hot-end and $57^{\circ} \mathrm{C}$ rejection temperatures. Second, the epoxy used to bond the magnets is rated at a higher temperature than that on the ASC-E2. Third, the ASC-L includes a passive balancer (Figure 1) and does not require an interconnect tube or external mass for operation. Passive balancers are simple, under-damped, spring mass oscillators, harmonically tuned for sympathetic resonance. Fourth, the ASC-L is considered a developmental convertor since the same quality system used on the ASC-E2s was not implemented due to time and budget constraints.

Limited design changes were made to the convertor to accommodate higher rejection temperature operation. The organics and materials for the internal limit sensor and piston were not changed for higher temperature operation but were deemed acceptable for short-term operation for $100 \mathrm{hr}$ or less at a PV temperature of $155^{\circ} \mathrm{C}$. The ASC-L underwent various tests at NASA Glenn as described in the sections that follow. 


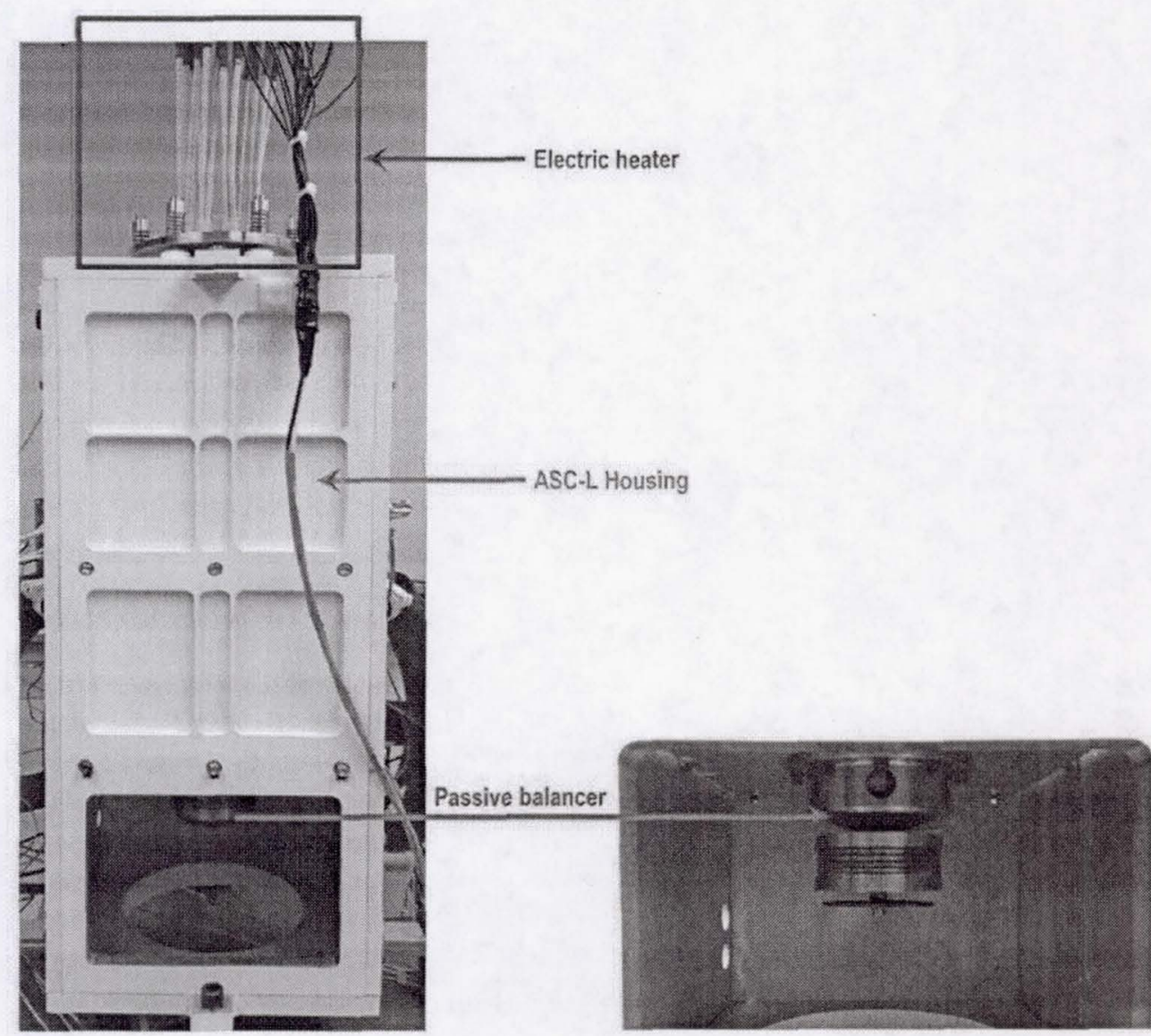

Figure 1.-ASC-L with passive balancer.

\subsection{Lunar Lander Simulated Test Stand}

The vibration produced by the ASC can affect the lander on which it is mounted. Pagnotta Engineering, Inc., was tasked with designing a test stand that simulated a lunar lander. This represents the first test stand in the Stirling Research Laboratory (SRL) at Glenn that attempts to characterize the effect of ASC vibration on a lander.

To characterize the dynamic effect of a single, operating ASC on a landing platform, the test stand was designed to simulate the dynamics of a potential lander and measure the force at the interface between the ASC and the lander and at the interface between the lander and the planetary surface. Figure 2 depicts a conceptual design for an ILN lander.

The test stand was designed to replicate the dynamic behavior of the conceptual lunar lander while avoiding the fundamental frequency of the ASC, $102.2 \mathrm{~Hz}$, as well as the first two harmonics, with significant frequency separation, mimic the total mass of the lander of $150 \mathrm{~kg}$, and provide isolation up to $20 \mathrm{~Hz}$ for the potential seismometer instrumentation. Providing adjustable stiffness and damping at both the interface between the ASC housing and the simulated lander and between the simulated lander and the planetary surface was also desirable to have the capability to simulate various landers.

Figure 3 shows the final design for the lunar lander simulated test stand. It has a total estimated mass of $175 \mathrm{~kg}$, a first vibrational mode at $30.36 \mathrm{~Hz}$, a second mode at $320.2 \mathrm{~Hz}$, and allows for adjustment of the stiffness and damping at both the interface between the ASC housing and lander simulator and between the lander simulator and ground. The test stand includes load cells at both of these interfaces for force measurement. While the ASC flexure utilizes a stainless steel plate in bending, the load fingers use a Sorbothane pad (Sorbothane, Inc.) to provide both stiffness and damping. 


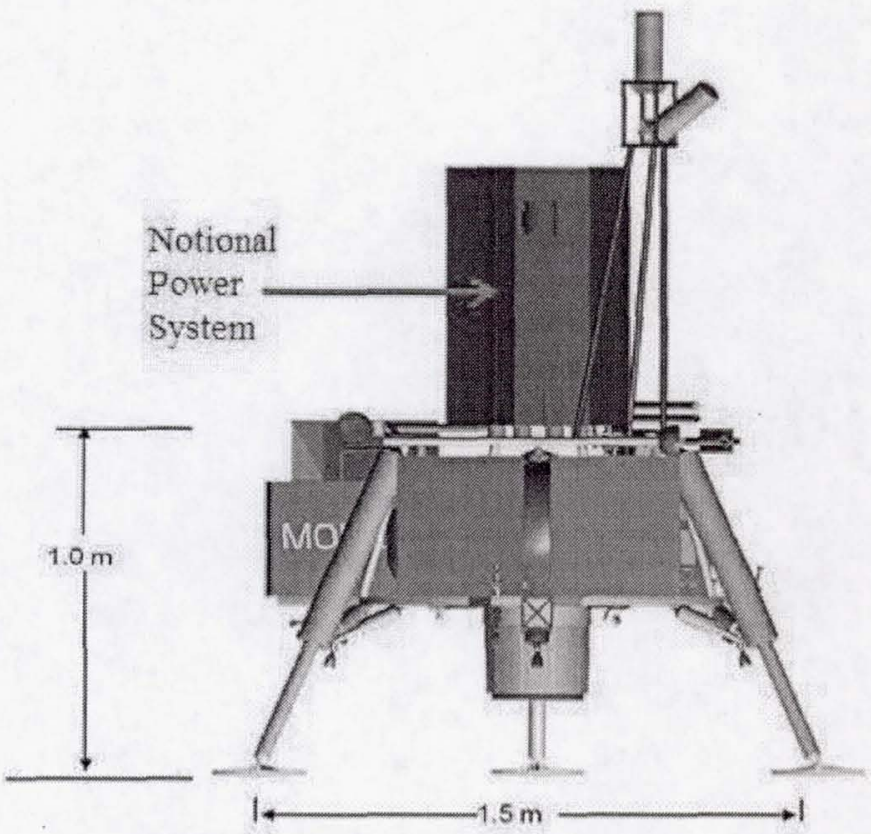

Figure 2.-Conceptual design for ILN lander.

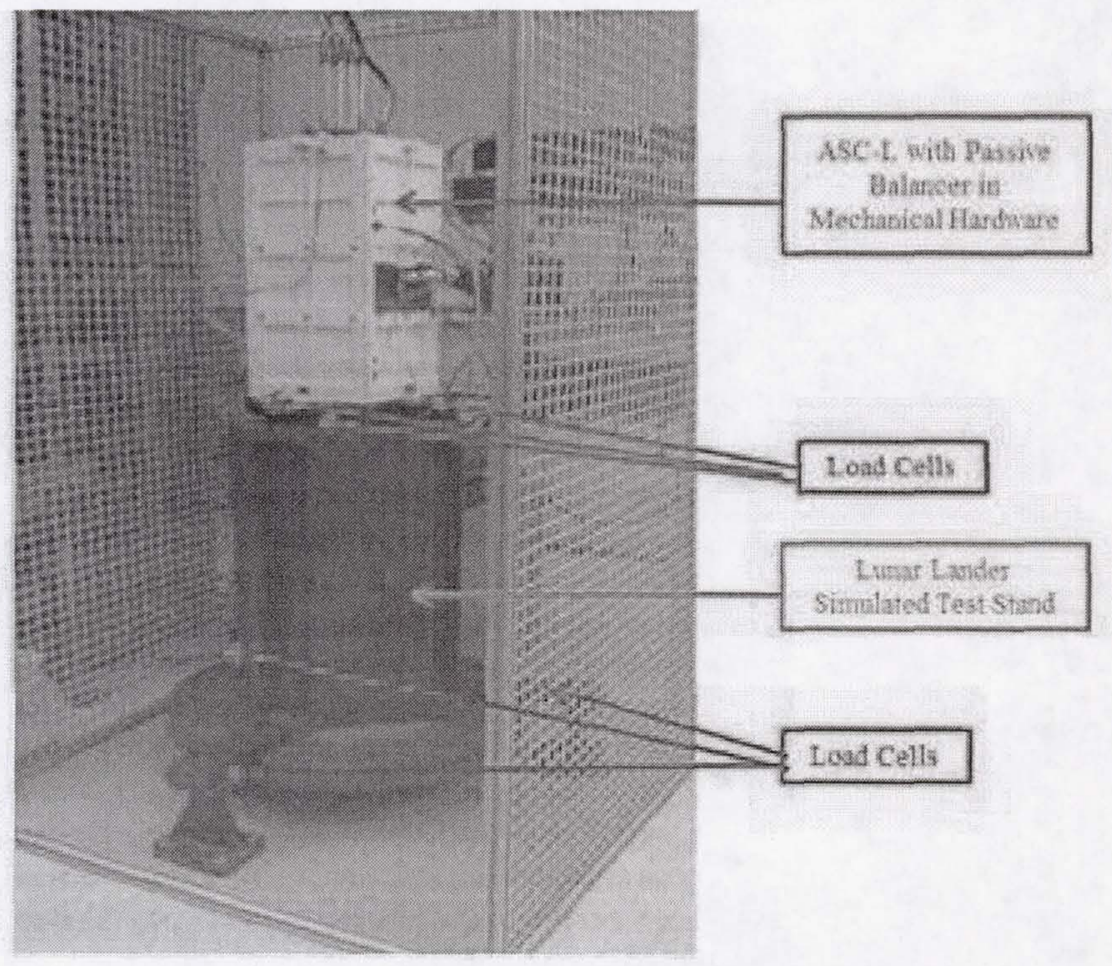

Figure 3. - Final design for lunar lander simulated test stand. 


\subsection{Single Convertor Controller}

The goal of the SCC task was to design and build a small, efficient, and reliable controller (Ref. 1) for use with a single ASC. The SCC maintains stable operation of the Stirling convertor. It regulates the alternating current $(\mathrm{AC})$ produced by the linear alternator of the convertor, provides a specified direct current (DC) output voltage for the spacecraft, and maintains operation with a stable piston amplitude and hot-end temperature. The controller allows adjustment of the operating point; the hot-end temperature or piston amplitude may be increased or decreased. The piston amplitude is maintained by varying the load with the regulation stage of the controller.

The SCC is designed for use with one ASC whereas the others used in the SRL at Glenn are intended for dual-opposed configured ASCs. The controller for a dual-opposed pair of convertors must synchronize the piston motion of the two convertors to minimize vibration as well as manage their operation. The controller was designed for flight use, but only a mechanically equivalent, nonflight EM was built.

Unlike most ASC controllers in the SRL, the SCC does not require a physical tuning capacitor to keep the stator current in phase with back electromotive force (EMF) voltage and piston velocity. These capacitors have a large mass and volume and are unattractive for spacecraft applications.

A block diagram of the SCC connected to a convertor and a typical redundant spacecraft is shown in Figure 5. The SCC consists of two identical controller boards packaged in separate chassis. One unit is actively in control of the convertor at all times, while the other is not powered unless needed to recover from a fault. Each controller board contains the power handling, data acquisition, signal processing, and secondary voltage conditioning circuits needed to control a convertor and deliver DC power to the spacecraft.

The SCC not only provides power to the spacecraft but it also must regulate ASC operation to avoid damage to internal components and maintain safe thermal conditions after fueling. The controller was designed with full redundancy to avoid potential overheating or damage to the internal structure. During SCC development, a functional failure mode and effects analysis (FMEA) listed possible functional failures in the circuits. The impact of such failures and mechanisms to detect and correct them were identified and implemented in the detailed design. A fault-tolerant SCC consists of two identical boxes, each containing a copy of the same circuit. In typical operation, one box is actively controlling the convertor, while the other is available as a backup in the event of a fault. The current best estimate mass of both boxes, without the interconnecting harness, is $2.27 \mathrm{~kg}$ using an Al-6061-T651 chassis and $2.00 \mathrm{~kg}$ if Mg-ZK60A-T5 material is used. Pictures of the SCC and EM circuit card in an assembly fixture are shown in Figure 4. The SCC underwent various tests at NASA Glenn as described in the sections that follow.
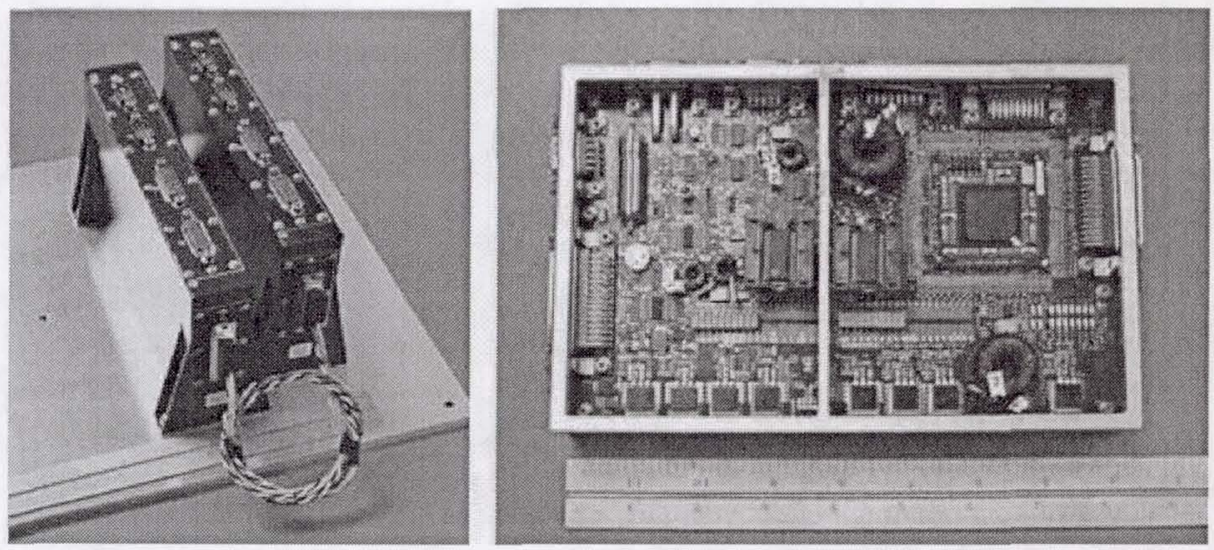

Figure 4.-SCC and EM Circuit Board. 


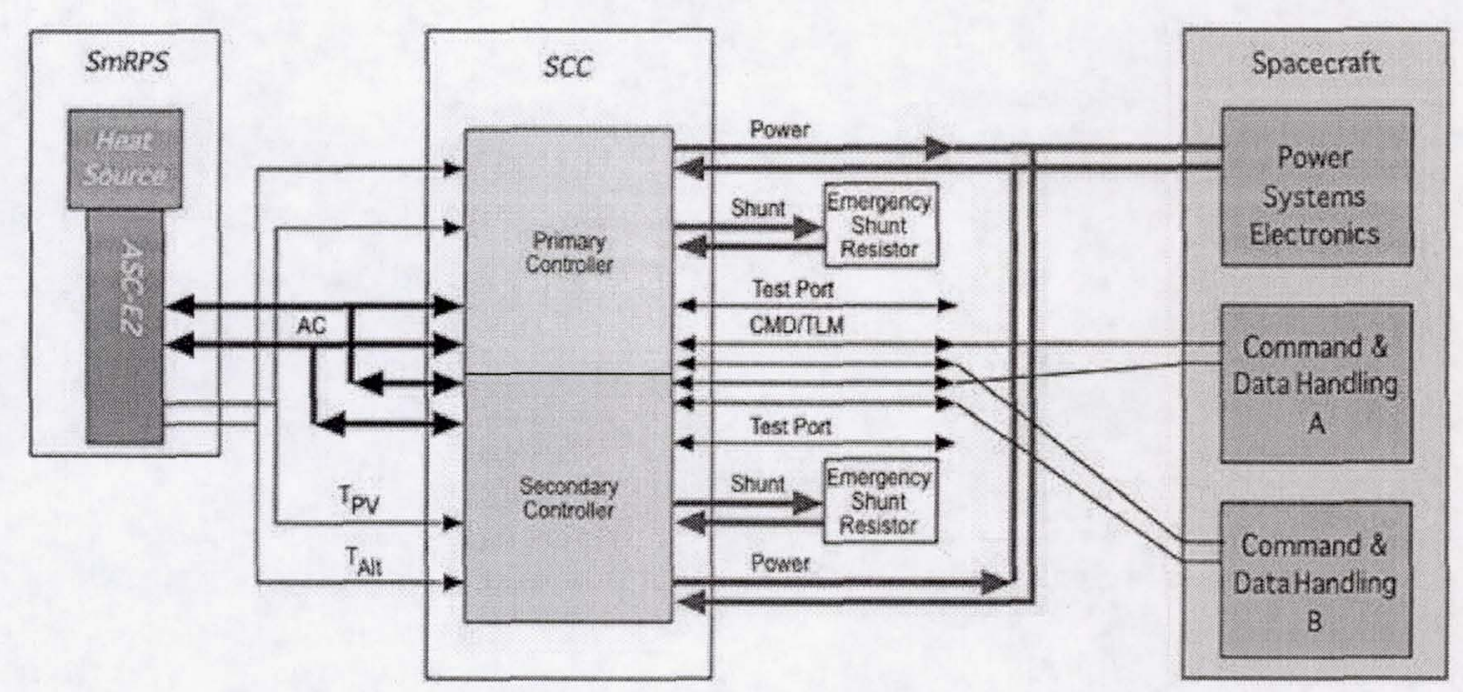

Figure 5.-Block diagram of a typical SCC redundant spacecraft application.

\subsection{Lunar-Derived Advanced Stirling Convertor (ASC-L) Testing}

\subsection{Temperature Performance Mapping}

Before delivering the ASC-L convertor to Glenn, Sunpower, Inc., completed the temperature performance map shown in Table 1. The performance map test points and results produced at Sunpower, Inc., were replicated in June 2012 at Glenn as shown in Table 2.

TABLE 1.-SUNPOWER, INC., ASC-L TEMPERATURE PERFORMANCE MAP DATA

\begin{tabular}{|l|c|c|c|c|c|c|c|}
\hline Mission phase & $\begin{array}{c}\text { Hot-end } \\
\text { temperature } \\
+0 /-2{ }^{\circ} \mathrm{C}\end{array}$ & $\begin{array}{c}\mathrm{CSAF} \\
\text { temperature } \\
\pm 2{ }^{\circ} \mathrm{C}\end{array}$ & $\begin{array}{c}\text { PV } \\
\text { temperature } \\
\pm 2{ }^{\circ} \mathrm{C}\end{array}$ & $\begin{array}{c}\text { Alternator } \\
\text { voltage, } \\
\mathrm{V}\end{array}$ & $\begin{array}{c}\text { Alternator } \\
\text { current, } \\
\mathrm{A}\end{array}$ & $\begin{array}{c}\text { Alternator } \\
\text { power, } \\
\mathrm{W}\end{array}$ & $\begin{array}{c}\text { Piston } \\
\text { amplitude, } \\
\text { mm }\end{array}$ \\
\hline $\begin{array}{l}\text { Beginning of } \\
\text { mission, max. }\end{array}$ & 847.2 & 89.5 & 97.9 & 14.14 & 10.37 & 75.2 & 4.09 \\
\hline Low reject & 846.8 & 46.2 & 54.8 & 11.18 & 8.91 & 60.2 & 3.58 \\
\hline High reject & 846.9 & 146.0 & 152.3 & 16.62 & 11.85 & 68.0 & 3.99 \\
\hline
\end{tabular}

TABLE 2.-GLENN ASC-L TEMPERATURE PERFORMANCE MAP DATA

\begin{tabular}{|l|c|c|c|c|c|c|c|}
\hline Mission phase & $\begin{array}{c}\text { Tot-end } \\
\text { temperature } \\
+0 /-2{ }^{\circ} \mathrm{C}\end{array}$ & $\begin{array}{c}\text { TSAF } \\
\text { temperature } \\
\pm 2{ }^{\circ} \mathrm{C}\end{array}$ & $\begin{array}{c}\mathrm{PV} \\
\text { temperature } \\
\pm 2{ }^{\circ} \mathrm{C}\end{array}$ & $\begin{array}{c}\text { Alternator } \\
\text { voltage, } \\
\mathrm{V}\end{array}$ & $\begin{array}{c}\text { Alternator } \\
\text { current, } \\
\mathrm{A}\end{array}$ & $\begin{array}{c}\text { Alternator } \\
\text { power, } \\
\mathrm{W}\end{array}$ & $\begin{array}{c}\text { Piston } \\
\text { amplitude, } \\
\mathrm{mm}\end{array}$ \\
\hline $\begin{array}{l}\text { Beginning of } \\
\text { mission, max. }\end{array}$ & 847.2 & 88.9 & 97.9 & 14.33 & 10.55 & 78.75 & 4.08 \\
\hline Low reject & 846.5 & 46.9 & 54.1 & 11.36 & 9.16 & 65.49 & 3.58 \\
\hline High reject & 846.4 & 144.2 & 152.9 & 16.17 & 11.75 & 65.53 & 3.99 \\
\hline
\end{tabular}

The ASC-L was delivered to Glenn with the Sunpower, Inc., mechanical hardware design, which included an insulation package, heater assembly, CSAF cooling jacket, and housing. This hardware was designed to allow for higher rejection temperature operation up to $147^{\circ} \mathrm{C}$. Due to the limited ASC-L design changes for high-temperature operation, high-rejection temperature operation was only performed for the temperature performance map; nominal convertor rejection temperature operation is $57^{\circ} \mathrm{C}$. The ASC-L was controlled by an AC bus power supply instead of the SCC since this type of controller was used by Sunpower, Inc. An AC bus power supply simulates the convertor being connected to an AC grid. The $\mathrm{AC}$ bus controller controls piston amplitude by varying the $\mathrm{AC}$ voltage and therefore, the load on the convertors. Increasing the AC voltage increases the piston amplitudes. The test results between Glenn and 
Sunpower, Inc., are comparable with the exception of the alternator power. The difference in alternator power measured at Glenn and Sunpower, Inc., is due to the location of the alternator power measurement at the feedthrough versus the connector. Upon completion of this test, the ASC-L was prepared for other component-level and integrated tests as will be discussed in the sections that follow.

\subsection{Electromagnetic Interference (EMI) Testing}

The ASC-L was tested in February 2013 for radiated EMI while controlled by first an AC bus power supply and afterwards the SCC. The goal was to compare for a baseline against second-generation-level Advanced Stirling Convertor (ASC-E2) radiated EMI test results and also to characterize the difference when controlled by the SCC. The baseline testing determined that there was, on average, an overall slight increase in AC magnetic field strength (as compared to the ASC-E2), but was otherwise very comparable. The EMI testing procedures were based on MIL-STD-461-C, referencing sections RE01, RE02, CS01, CS02, CS06, CE01, and CE03. AC magnetic field measurements were taken using a Macintyre Electronic Design Associates (MEDA) MGCH-2 magnetic probe with a MEDA SAM-3 amplifier as well as a 13.7-cm SAS-200/56 (450) loop antenna by AH Systems. DC magnetic field measurements were taken with a F.W. Bell HTM99-0608 Hall Effect Probe with a F.W. Bell 9550 Gauss Meter. AC electric field measurements were taken using an active rod antenna (EMCO 3301B) or a diskcone antenna (Antenna Research SAS-2A/m) depending on the frequency range being focused on. Conducted emission tests used AH Systems current probes, namely BCP-200/510 for low frequencies and BCP-200/511 for high frequencies. The conducted susceptibility testing used a Marconi 2031 generator.

During AC magnetic field testing, the SCC increased the radiated emissions from the ASC-L marginally $(\sim 0.5 \mathrm{dBpT})$, but the main effect was an introduced spike at $23 \mathrm{kHz}$, the pulse width modulation (PWM) switching frequency of the SCC, plus harmonics. The data is contained in the NASA Glenn EMI Test Data Report GRC-EMI-RPT-342 (this also contains the data for the SCC susceptibility and conducted emission tests mentioned later in this report). Figure 6 shows the difference in measured magnetic fields when ASC-L is controlled by the AC Power Supply as compared to the SCC.

During AC electric field testing, the SCC decreased the $102.2 \mathrm{~Hz}$ dominant spike but increased the $204.4 \mathrm{~Hz}$ spike, with associated harmonics. It also injected a $23-\mathrm{kHz}$ spike (likely due to the PWM switching as mentioned above), and introduced broadband noise from $\sim 400 \mathrm{kHz}$ through $\sim 15 \mathrm{MHz}$. As this was a general characterization test, there has not been much effort to identify the sources of the changes introduced. Figure 7 and Figure 8 show the effect on axial electric field measurements between $\mathrm{AC}$ bus control and SCC control.
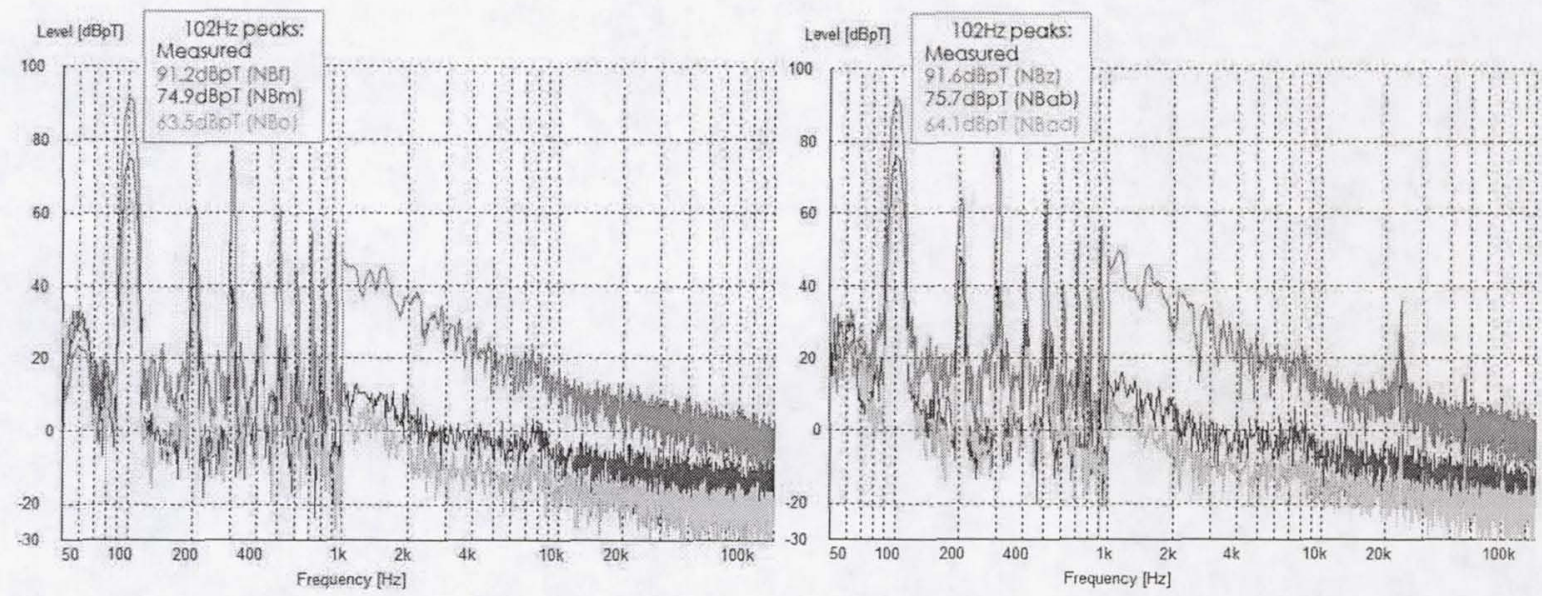

Figure 6.-Axial AC magnetic fields, AC bus (left) versus SCC (right). $1 \mathrm{~m}$ (pink), $2 \mathrm{~m}$ (blue), and $3 \mathrm{~m}$ (green). 


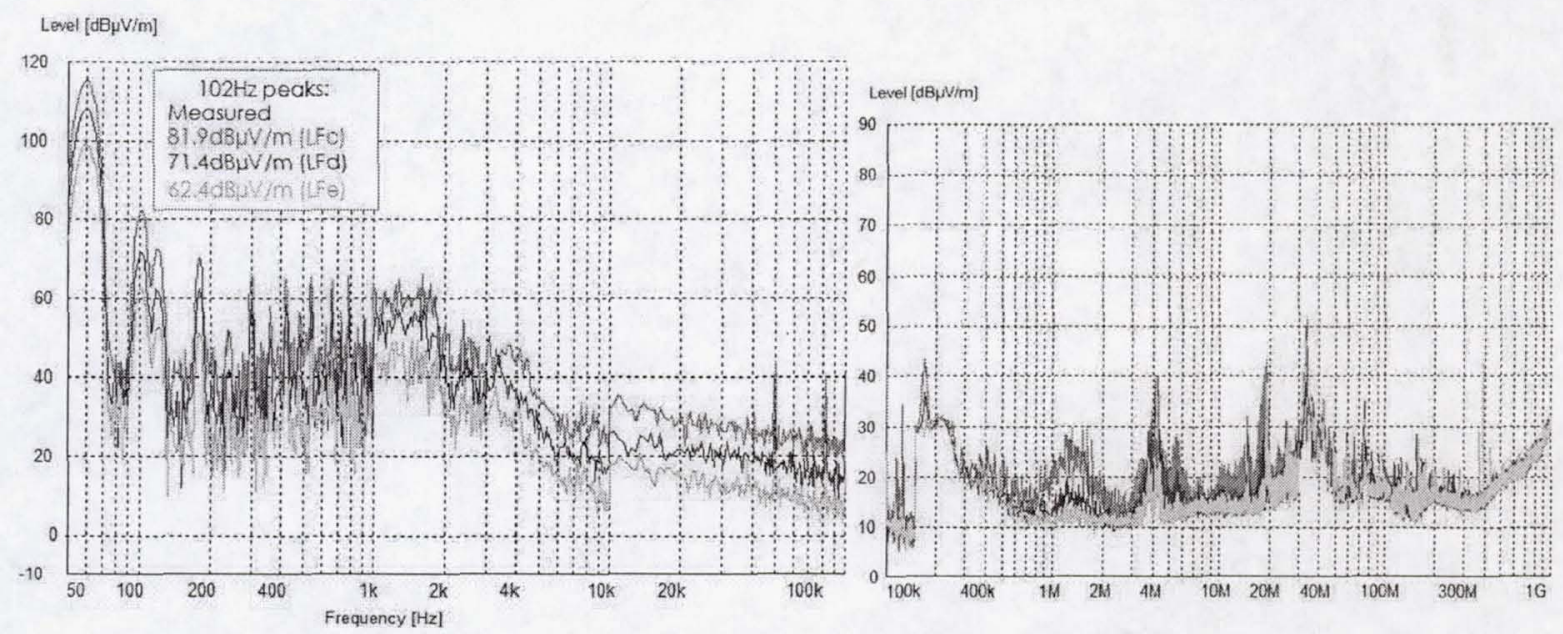

Figure 7.-Axial electric field measurement, AC bus control. $1 \mathrm{~m}$ (pink), $2 \mathrm{~m}$ (blue), and $3 \mathrm{~m}$ (green).

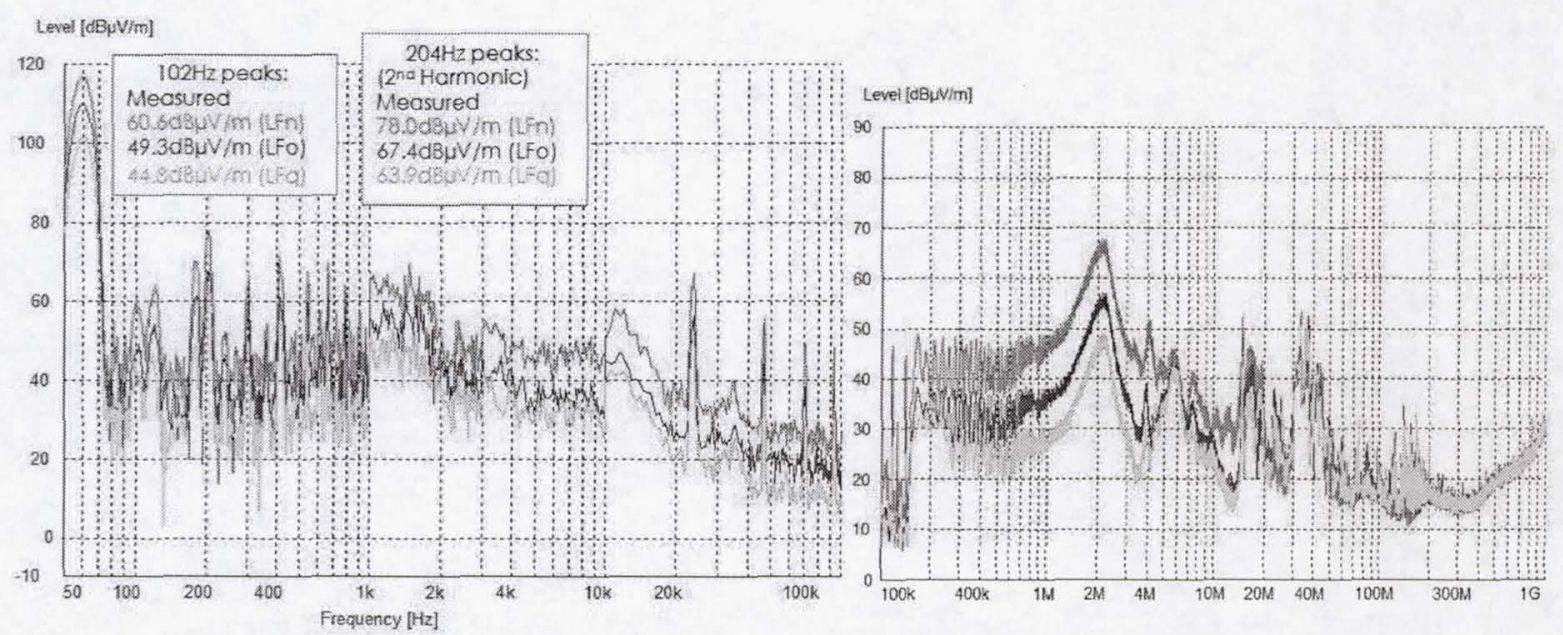

Figure 8.-Axial electric field measurement, SCC control. $1 \mathrm{~m}$ (pink), $2 \mathrm{~m}$ (blue), and $3 \mathrm{~m}$ (green).

\subsection{Single Convertor Control Testing}

\subsection{Fault Testing}

The SCC not only provides power to the spacecraft but it also must regulate ASC operation to avoid damage to internal components and maintain safe thermal conditions after fueling. The controller was designed with full redundancy to avoid potential overheating or damage to the internal structure. Spacecraft power needs may briefly exceed the capacity of the SRPS power source. There are many causes of such events; examples include activating thruster valves, sudden momentum wheel speed changes, telemetry downlink transmission, in-rush current surges when activating loads, and bursts of science data collection are among many such possibilities. If auxiliary power is not supplied from another source, the power bus voltage may be pulled too low and trigger a spacecraft fault. A battery frequently acts as the auxiliary power source to ensure that an adequate bus voltage is maintained during these power transients. Alternatively, a large capacitor may provide backup power if the expected power transients are 
short and the energy storage capacity of the capacitor is adequate. Thus, the SCC was required to support either a battery or capacitive power bus spacecraft architecture.

During SCC development, a functional FMEA listed possible functional failures in the circuits. The impact of such failures and mechanisms to detect and correct them were identified and implemented in the detailed design. The scope of potential issues were not limited to internal controller failures but extended outside to include impacts from the spacecraft and the engine. Recovery from a fault is based on switching from the controller board that detected the fault to the backup board. After detecting the $\mathrm{H}$ bridge fault and isolating the failed controller, modeling showed that the backup controller had less than $20 \mathrm{~ms}$ to reestablish proper operation of the convertor. Modeling also showed that the open/short must be removed in less than $5 \mathrm{~ms}$ to avoid internal damage to convertor components.

The fault detection and correction mechanisms in the controller protect the convertor and spacecraft from damage while recovering from a fault. Power flows from the convertor through an electronic switch that acts as an AC circuit breaker. The AC circuit breaker is opened in the event of a fault to isolate the convertor from the failure and allow the redundant board to initiate control. An electronic DC circuit breaker utilizing two FET switches will isolate the controller board from a spacecraft fault and isolate the spacecraft from an internal controller fault. While the DC breaker is open, convertor power flows to an external shunt resistor controlled using PWM to maintain a fixed $\mathrm{H}$-bridge output voltage. A combination of analog circuits, field programmable gate array (FPGA) logic, and microcontroller software monitor SCC operation and detect and correct potential faults.

Analysis was completed to determine methods for achieving hot swap functionality. Hot swap refers to changing a failed controller card while the active controller card maintains operation of a convertor operating at full power. Due to hot swap capability, each controller card requires its own set of harnessing.

The SCC successfully handled various fault conditions, including high or low spacecraft power consumption, total open load or short circuit, and replacing a failed SCC card while the backup maintains control of the ASC. These tests were completed with an ASC-1 \#4, early Sunpower, Inc., developmental convertor. The main difference, as far as the controller is concerned, between the ASC-L and ASC-1 \#4 is the operating frequency. The ASC-L operates at a frequency of $102.2 \mathrm{~Hz}$ and ASC-1 \#4 at $103 \mathrm{~Hz}$. However, the SCC can be commanded to operate in the frequency range of 99.0 to $104.7 \mathrm{~Hz}$.

The SCC fault testing, in November 2011 and March 2012, included spacecraft disconnect, spacecraft bus voltage variation, AC circuit breaker open load, and hot swap. The results of these tests can be seen in Figure 9 to Figure 12. The spacecraft disconnect test confirmed the SCC's ability to operate in the fueled configuration. During fueling, the SCC will be disconnected from the spacecraft and will dissipate power in a shunt resistor. The DC bus voltage variation test confirmed the SCC's ability to maintain convertor power output stability over a range of DC bus voltages. The AC circuit breaker open load test is one of many open/short circuit fault tests performed on the SCC. This verifies the SCC's ability to handle an open/short either on the ASC or spacecraft side. The hot swap test confirmed the SCC's ability to maintain ASC control while replacing a failed controller card. Additional testing included verifying the ability of the SCC to maintain convertor control while going over and under the acceptable DC bus voltage range, successful power transfer from the spacecraft to the shunt resistor, and recovery from the fault. The SCC attempts to reconnect to the spacecraft and connects when the spacecraft voltage reaches an acceptable range. 


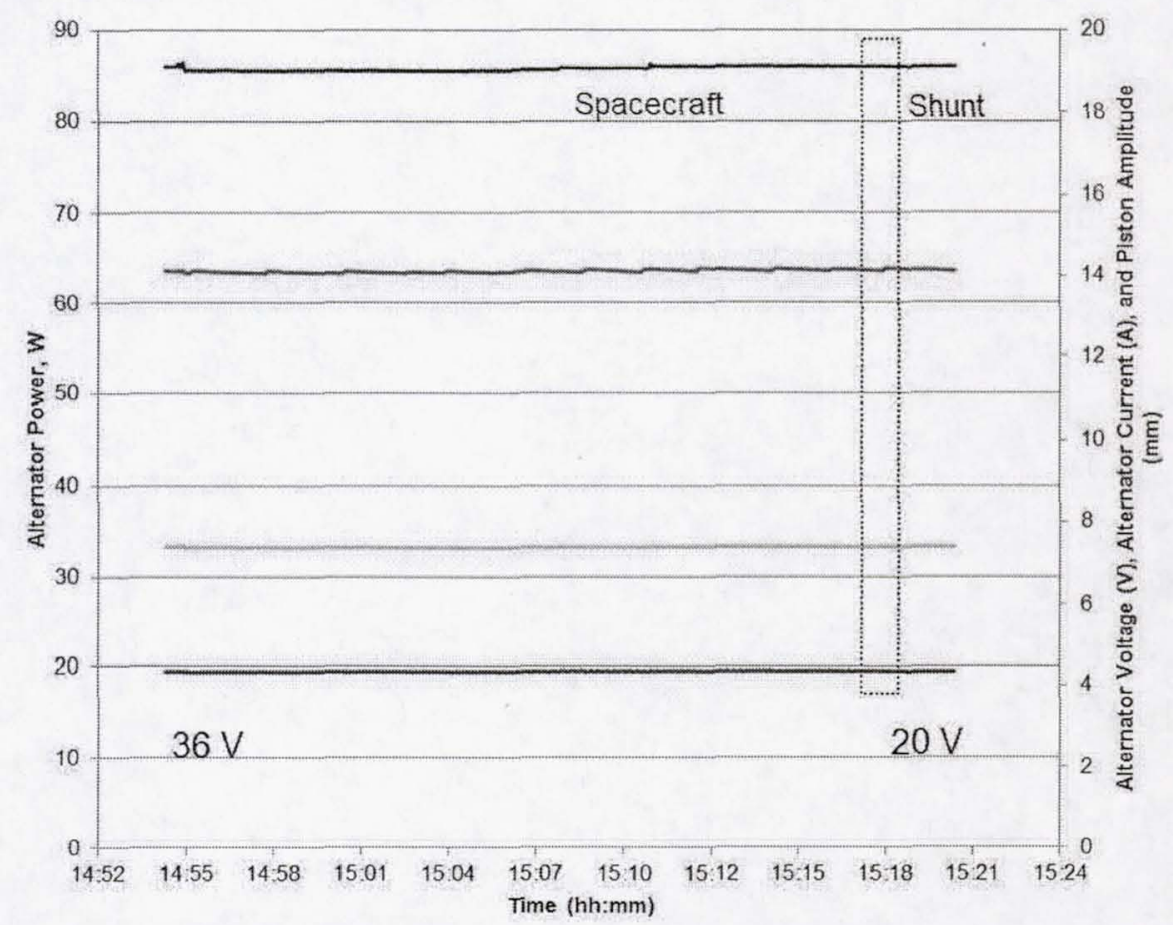

Figure 9.-Spacecraft bus voltage variation. Piston amplitude (blue), alternator voltage (red), alternator current (green), and alternator power (black).

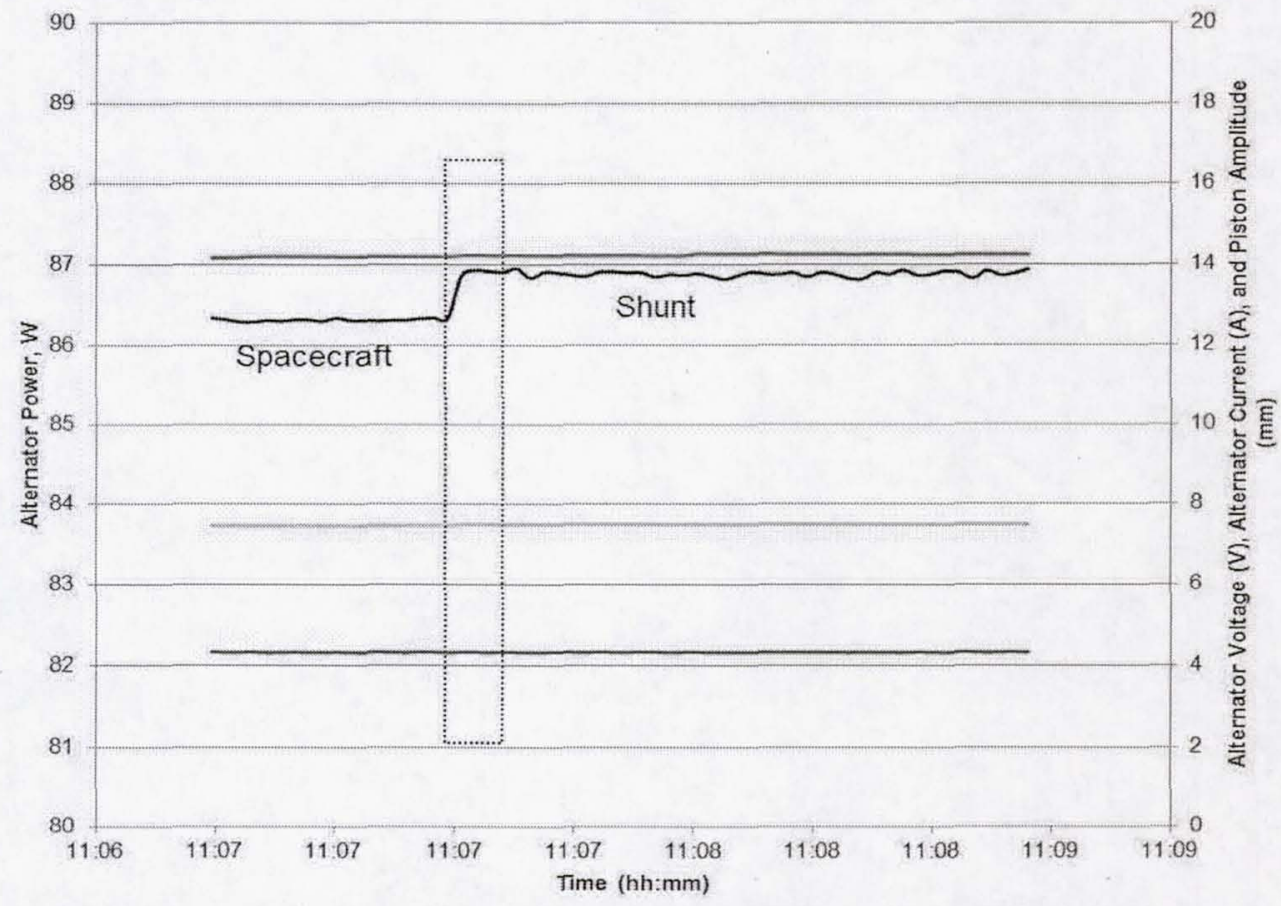

Figure 10.-Disconnect from the spacecraft. Piston amplitude (blue), alternator voltage (red), alternator current (green), and alternator power (black). 


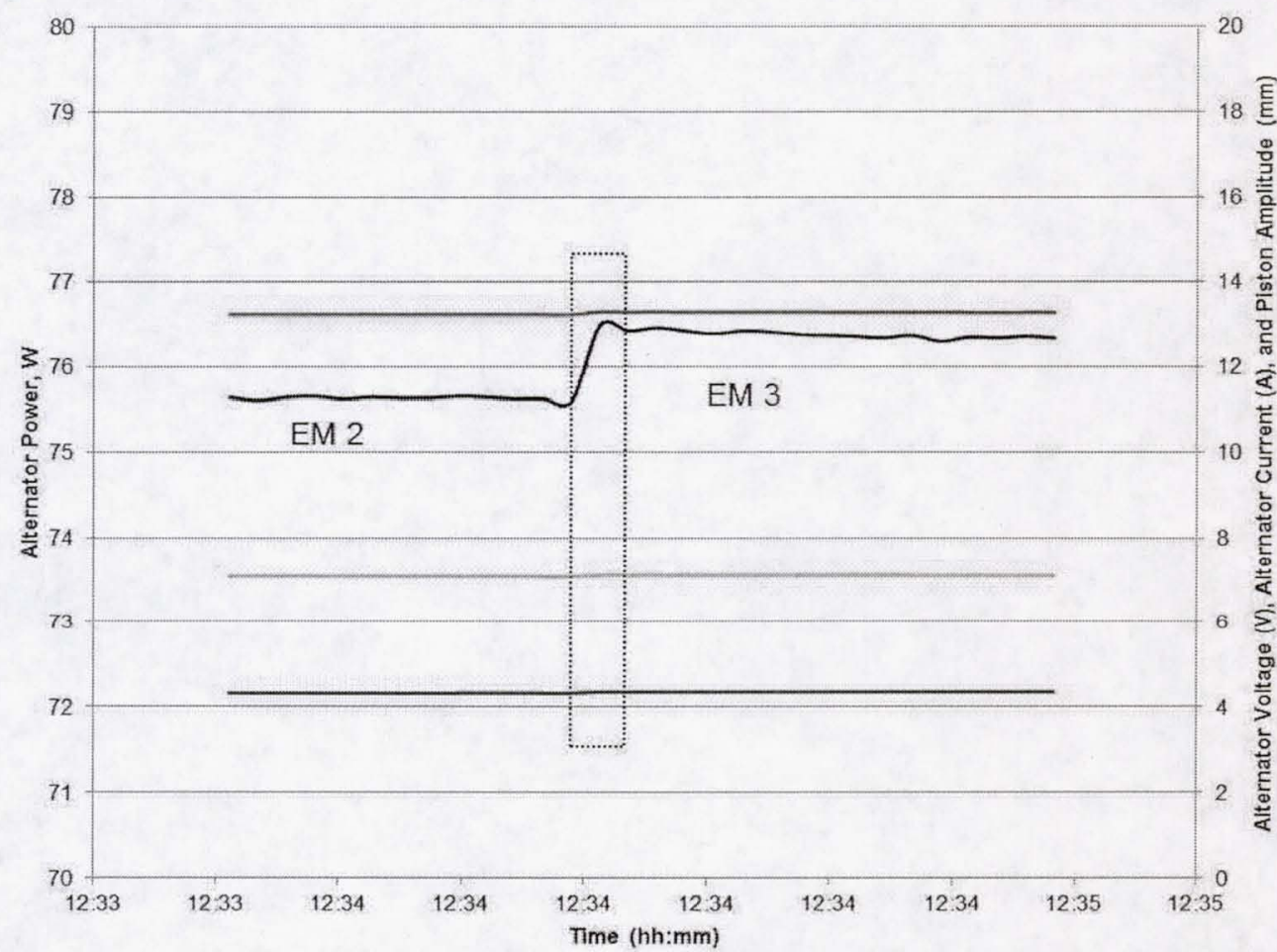

Figure 11.-AC circuit breaker open load fault. Piston amplitude (blue), alternator voltage (red), alternator current (green), and alternator power (black).

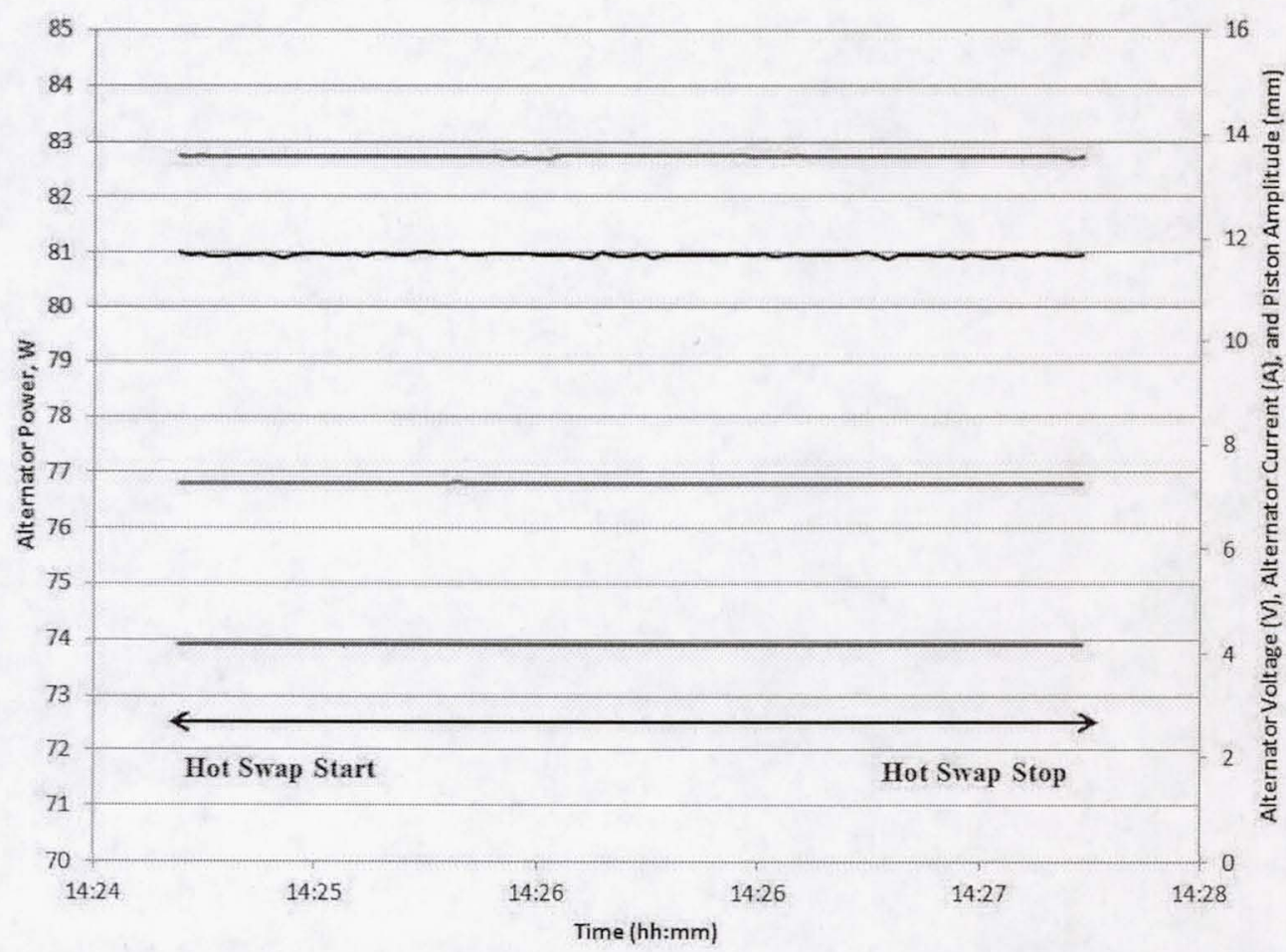

Figure 12.- Hot swap. Piston amplitude (blue), alternator voltage (red), alternator current (green), and alternator power (black). 


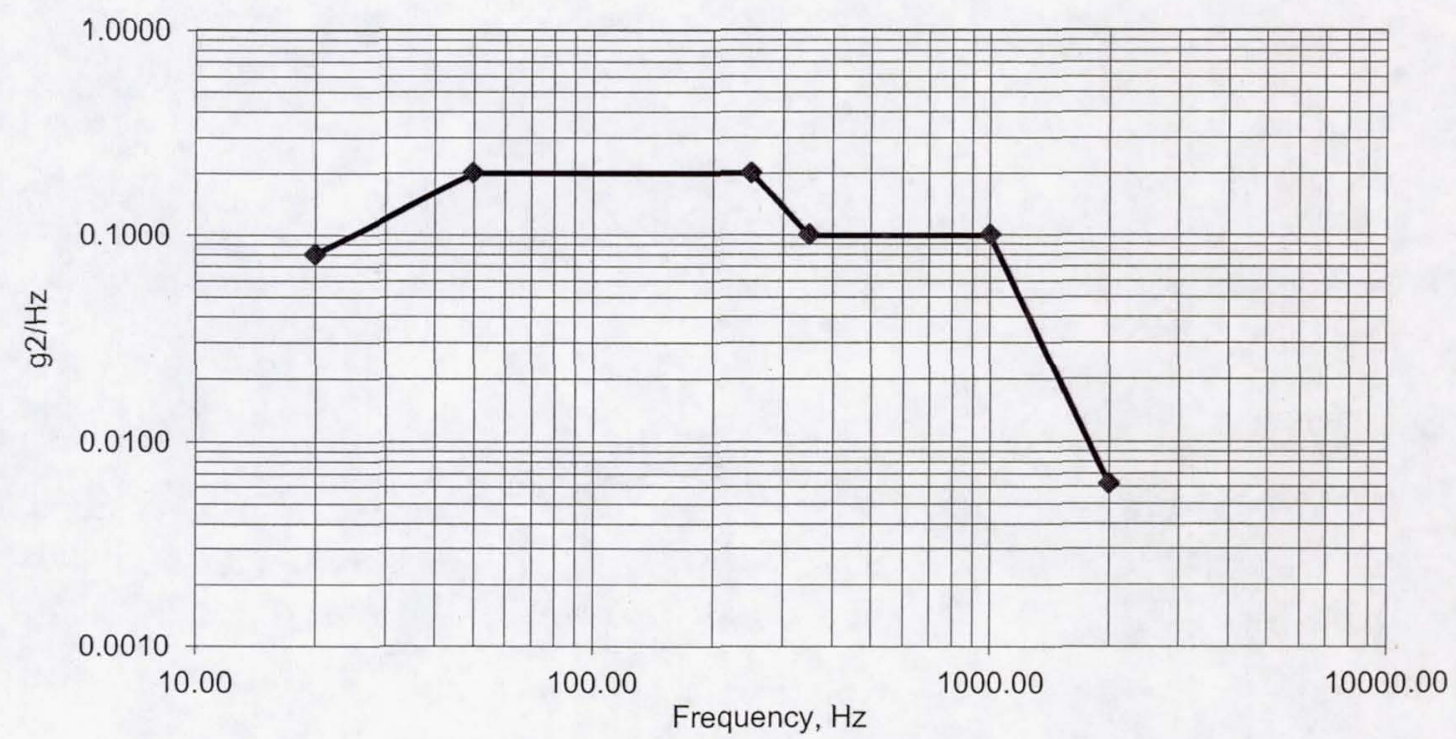

Figure 13.--Random vibration profile.

\subsection{Flight Acceptance Vibration Testing}

The ASC-L was subjected to flight-acceptance-level vibration testing (Figure 12) under SCC control in January 2013. The goal of the testing was to achieve qualification-level vibration. Flight-level vibration is $-3 \mathrm{~dB}$ from qualification-level vibration. The convertor performed acceptably during the flight-level vibration testing with no change in performance noted when compared to the pre-vibration test run. The SCC maintained safe piston margins when subjected to flight-acceptance levels. However, the postvibration data analysis noted that the $\mathrm{ASC}-\mathrm{L}$ was producing very high levels of current (near $25 \mathrm{~A}_{\mathrm{rms}}$ ) during peak accelerations. This high level of current was near the saturation point of the SCC's current sensor, and is something that will be addressed in future controllers. Due to the high levels of current, the test ended at flight-acceptance level. This data was captured in the Glenn Structural Dynamics Lab Test Report SDL-TR-13-03. Figure 13 shows the random vibration profile that was used during the test.

Due to the nonlinear output of the ASC piston sensor (APS), the real-time decision to abort during a vibration test has relied in the past on either an alternate position sensor being used or on ancillary data (current, etc.). The data acquisition (DAQ) system in the test rack samples during a 2-sec window and outputs a calculated value - clearly not appropriate for a real-time abort decision on a random vibration test. An independent nearly real-time APS processor was developed to provide a more linear piston position output that could be viewed on an oscilloscope to make abort decisions during the test run based purely on piston proximity to hard stops inside the ASC. Analysis of a data post test showed that while the processor output lagged an actual piston peak position by 3 to 4 cycles (at $102.2 \mathrm{~Hz}$ ), the data was provided to the operator quickly enough to shut down the test before any actual contact events occurred. 


\subsection{Susceptibility and Conducted Emissions Testing}

The SCC was tested for conducted line emissions while operating the ASC-L using test procedures based on MIL-SPEC-461C CE01 and CE03. The majority of peaks were detected at $204 \mathrm{~Hz}$ (two times convertor operating frequency) with 4 to 5 harmonics, at $\sim 23 \mathrm{kHz}$ (approx. SCC PWM switching frequency) with several harmonics and at $\sim 700 \mathrm{kHz}$. There was no discernible difference in conducted emissions between the different operating modes of the SCC nor on the power versus return leads. There was a significantly higher $(\sim 40 \mathrm{~dB} \mu \mathrm{A})$ level of noise pre-capacitor bank versus post-capacitor bank as shown in Figure 14.

Additionally, the SCC was subjected to conducted EMI susceptibility testing using test procedures based on MIL-STD-461C CS01, CS02, and CS06. To protect the ASC-L hardware against a loss of control event, the convertor simulator was used to provide power to the SCC and a resistive test load was used to pull full power during the duration of the test without using an electronic load. The convertor simulator was developed by APL and simulates the operation and electrical behavior of an ASC in real time via a combination of hardware and software. The CS01 and CS02 tests are power limited to $1 \mathrm{~W}$ and voltage limited to $1 \mathrm{~V}_{\mathrm{rms}}$ - both tests typically experienced voltage limiting in the lower $\mathrm{kHz}$ range during CS02 where power limiting dominated. During conducted susceptibility testing, there were no noticeable performance effects. Output voltage change, controller latch-up, or loss of communication were all monitored and did not occur. Figure 15 details the profile of two of the pulses applied to the power path during CS06 and are similar to other pulse events.

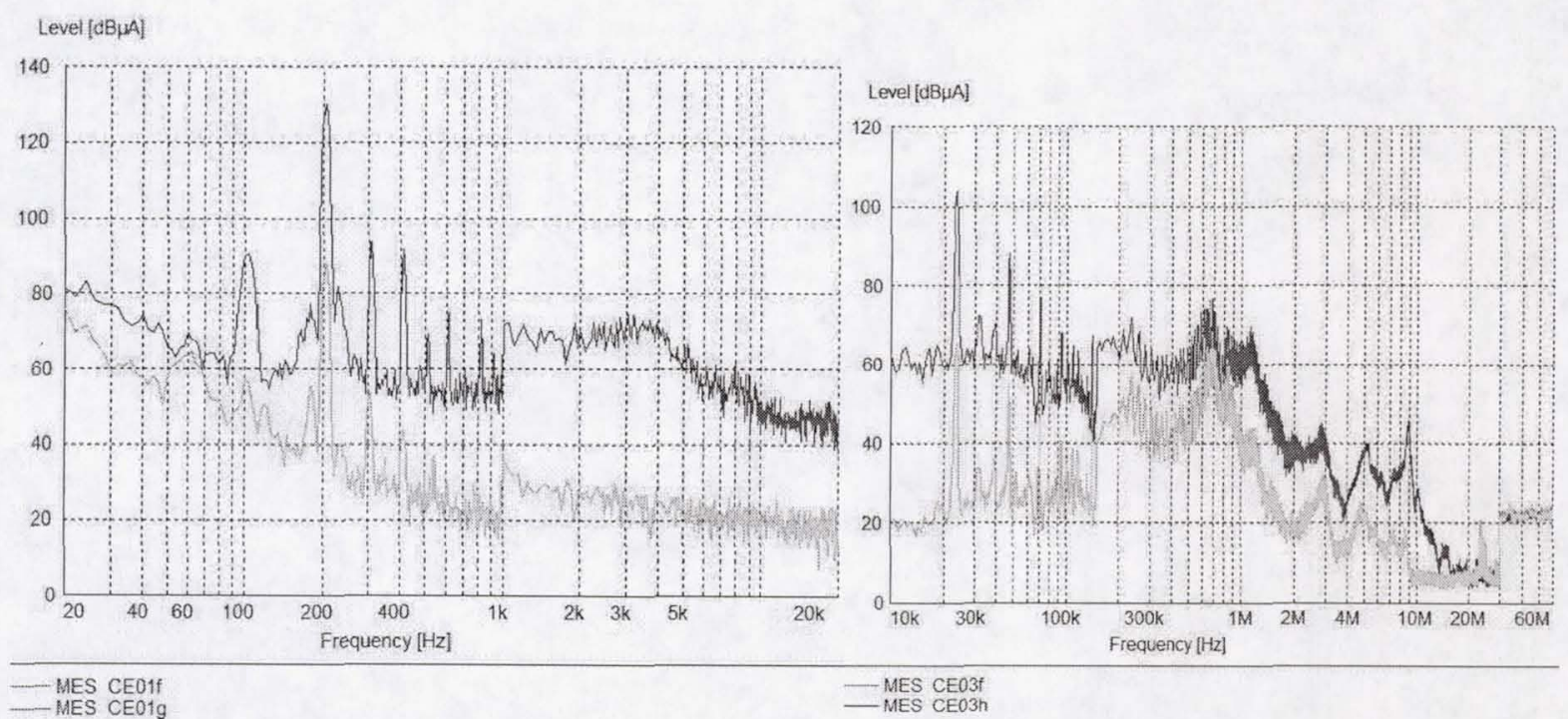

Figure 14.-CE01 and CE03 comparison of pre-capacitor (blue) and post-capacitor banks (green). 

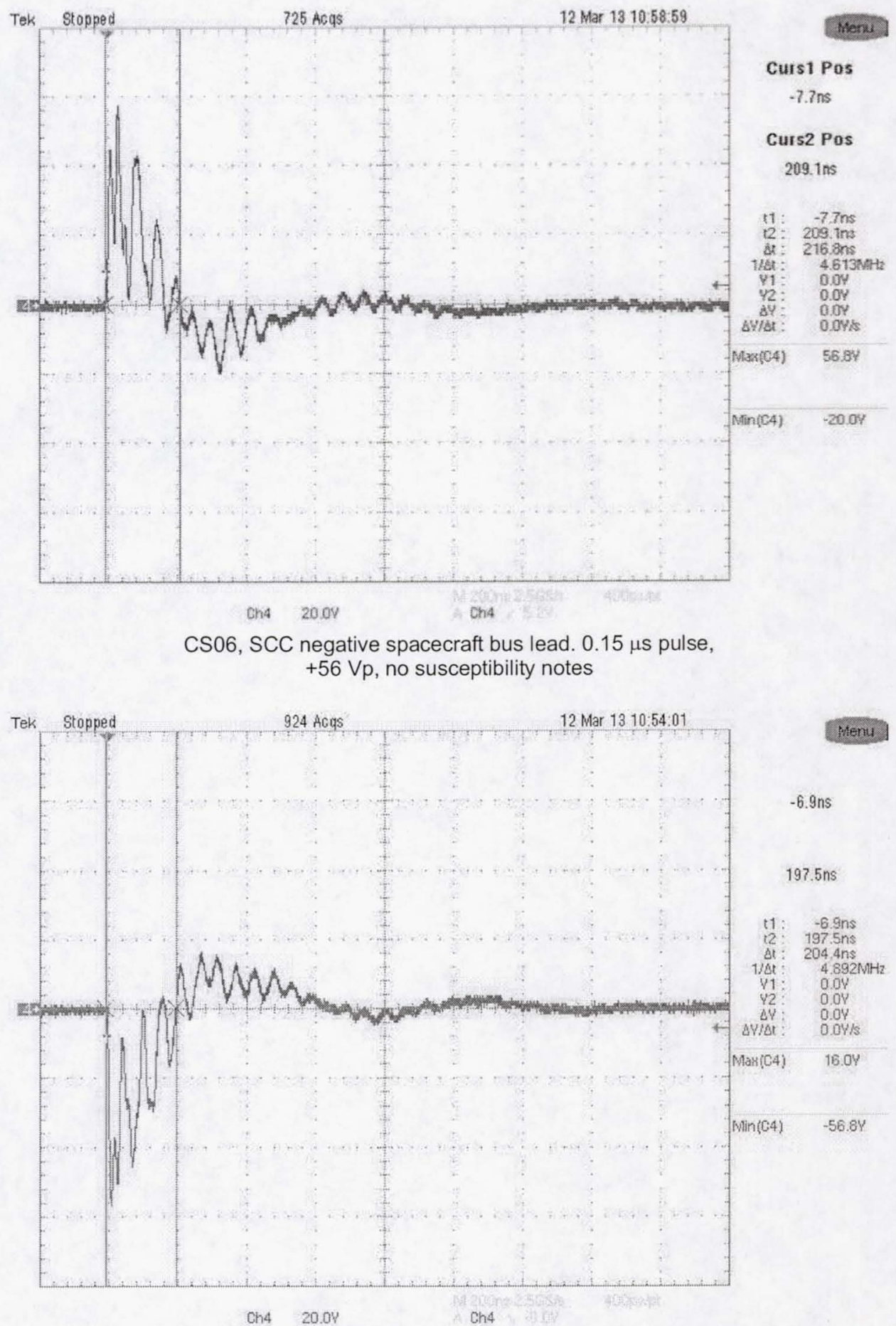

CS06, SCC negative spacecraft bus lead. $0.15 \mu$ s pulse, $-56 \mathrm{Vp}$, no susceptibility notes

Figure 15.-CS06 positive and negative pulse on power return lead. 


\subsection{Integrated Testing}

\subsection{Passive Balancer Tuning}

The ASCs tested in the SRL at NASA Glenn are tested both as single units and dual-opposed pairs. A single ASC requires mounting to a large mass to reduce vibration produced by the convertor. A dualopposed pair is mounted with the heater heads facing outward and the PV sections rigidly attached to each other. This configuration permits dynamically balanced operation where the piston's motions are equal but opposite in direction. However, a single ASC mounted to a large mass is impractical for spacecraft applications. Therefore, under the SRPS project, Sunpower, Inc., designed a passive balancer to replace the large mass and spring system used to absorb the vibration produced by the ASC. This is the first integration of an ASC with a balancer.

The passive balancer is tuned to balance the convertor force at a specific operating point, including piston amplitude, rejection temperature, balancer temperature, and convertor operating frequency. The ASC-L with the passive balancer is mounted to the lunar lander simulated test stand. The load cells mounted at the base of the test stand and between the simulated lunar lander simulated test stand and the ASC-L housing provide data on the vibration emitted by the convertor to the lander and lunar surface.

Prior to tuning the passive balancer in May 2103, a tap test was performed at Glenn to characterize the lunar lander simulated test stand. During this test, several accelerometers mounted on the various components of the test stand, including the ASC-L housing, the lunar lander mass simulator, and the floor, recorded the accelerations resulting from taps imparted to the structure at different locations. This test verified that the frequencies and shapes of the system modes match those predicted in the design analysis.

When designing the passive balancer, the dynamics of the lunar lander simulated test stand must also be considered. The operation of the balancer is effected by the compliance between the ASC and the test stand. If the compliance is greater than $9000 \mathrm{~N} / \mathrm{mm}$ then the balancer will not work as a vibration canceller. If the compliance is less than $9000 \mathrm{~N} / \mathrm{mm}$, the vibration characteristic of both the test stand and balancer is varied by the balancer. At the time the test stand was designed this compliance requirement was not known and therefore was designed with compliance greater than $9000 \mathrm{~N} / \mathrm{mm}$. Since, as mentioned in Section 2.0, the lunar lander test stand was designed with an adjustable stiffness this compliance could be changed. After this adjustment, the passive balancer was tuned to operate at $850{ }^{\circ} \mathrm{C}$ hot-end temperature, $57^{\circ} \mathrm{C}$ rejection temperature, 4.25 -mm piston amplitude, and $102.2 \mathrm{~Hz}$ operating frequency. This operating point resulted in a passive balancer temperature of $35^{\circ} \mathrm{C}$. As part of the tuning process, an accelerometer mounted on the ASC-L housing was used to find an operating frequency that minimized acceleration. The convertor operating frequency was changed, while the convertor was stalled, in $0.01 \mathrm{~Hz}$ increments up to $\pm 0.5 \mathrm{~Hz}$ deviation from the convertor operating frequency. Once the frequency was determined, a calculation was performed to determine the mass needed to minimize the force produced by the ASC. This mass was installed on the ASC to characterize its ability to reduce the force exerted on the lunar lander test stand and planetary surface.

The tuning resulted in a force reduction between the ASC-L housing and lunar lander simulated test stand from 253.4 to 111.6 Newtons and a reduction between the lunar lander and planetary surface from 265.8 to 118.7 Newtons. Options to further reduce this force are being considered. The SRPS operates $24-\mathrm{hr} / 7$ days per week without the passive balancer since the temperature regulation in the lab is not suitable to meet the balancer temperature limitation of $\pm 4{ }^{\circ} \mathrm{C}$. If the balancer temperature limitation is exceeded, the balancer will resonate and cause potential damage to the ASC-L. Other balancer options without this temperature limitation are being considered. 


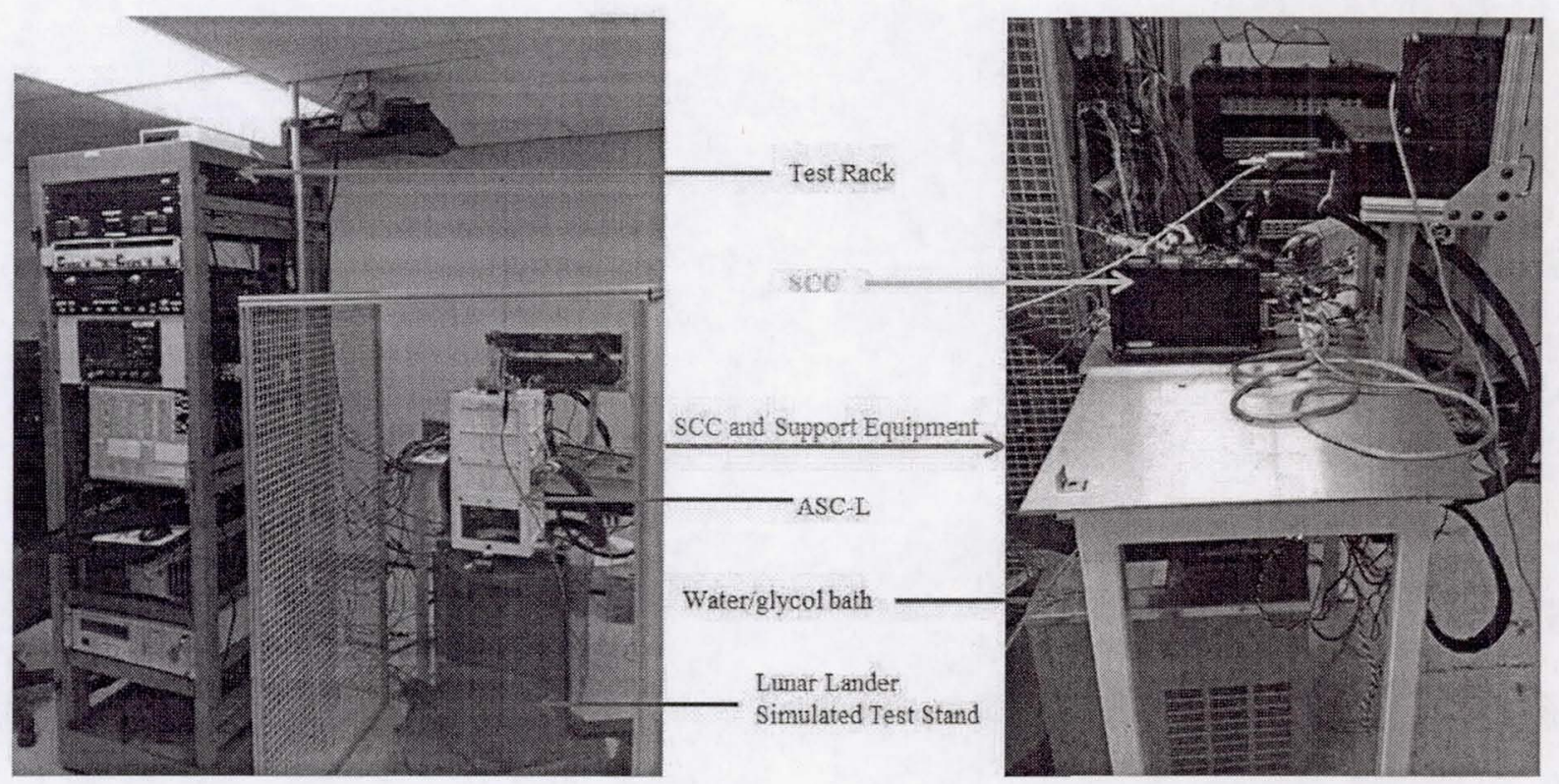

Figure 16.-SRPS extended operation setup.

\subsection{Extended Operation}

Extended operation (Ref. 2) of ASCs has been an ongoing effort at NASA Glenn since 2003. This effort was initiated to demonstrate the life and reliability of Stirling convertors. Extended operation involves continuous, unattended convertor operation over a period of thousands of hours. The test rack provides the means for measuring and collecting data for observing operating trends. In addition, it provides convertor control and safe operation. Figure 16 shows the SRPS test rack in Glenn's SRL.

The SRPS test rack is designed to operate either an AC bus power supply controller or the SCC. Each test rack allows the adjustment of operating conditions, including hot-end temperature, rejection temperature, and piston amplitude. Each test article was instrumented to measure these parameters in addition to output characteristics such as alternator voltage, current, power, and operating frequency. The hot end of the convertor is heated with electric cartridge heaters (Figure 1), and the cold end is maintained with a water/glycol bath.

The data system utilizes National Instruments' LabVIEW-based DAQ hardware and software to acquire data and monitor the test. It displays and records data on a computer, collects and saves data in various timeframes, calculates parameters with received data, and provides safety to the convertors. The DAQ software, which was developed to operate in unattended mode, can control the support systems without user intervention.

Data collection allows for detailed analysis of convertor operation. To achieve this, LabVIEW collects and displays several parameters including

- Heater voltage and current

- Electric heat-source temperature

- Hot-end temperature

- Cold-end temperature

- Ambient temperature

- PV temperature

- Alternator root mean square (RMS) voltage, RMS current, and power

- Piston amplitude

- Operating frequency 
- AC bus power supply controller voltage and current

- Power factor

- Heater power

A complete data record of these parameters is stored every hour. In addition, the DAQ system maintains a buffer of data recorded over the last $24 \mathrm{hr}$ at a $2-\mathrm{sec}$ scan rate, records an average of the data over the last $5 \mathrm{~min}$ of every hour, and allows these data to be stored manually as needed for detailed analysis. From the stored data, numerous parameters are calculated including

- Heater resistance and power

- System efficiency

- Average hot-end temperature

- Cold-end temperature

- Piston amplitude

- Net heat input

The DAQ software collects and displays various telemetry parameters. In addition, it allows for the following SCC commanding:

- Changing the voltage applied to the convertor to start piston motion, Vm

- Convertor operating frequency

- Disconnect from the spacecraft

- Connect to the spacecraft

- Operation with or without the backup controller card

- Open load or short circuit fault injection

Convertor hot-end temperature is controlled by a hot-end thermocouple input to a Partlow proportional integral derivative (PID) temperature controller. The PID temperature controller varies the voltage of a programmable Xantrex DC power supply connected to cartridge heaters in a heat source block to maintain constant hot-end temperature. The PID temperature controller is programmed to limit the rate of change in temperature to $1{ }^{\circ} \mathrm{C} / \mathrm{sec}$.

Electronics in the SCC place requirements on the power path line resistance. The test rack accommodates this requirement in two ways. First, the power panel is mounted as close to the convertor as possible to reduce the length of wire in the power flow path. Second, external current sensors are used for current measurements. These modifications allow measurements to be taken close to the convertor.

The SCC relies on a DC electronic load to sink power in an output voltage range between 22.0 and $36.0 \mathrm{~V}_{\mathrm{dc}}$ and is determined by the end user. The SCC will track to this voltage providing power as a constant-power source, and will sense a bus overvoltage condition. The SCC will provide constant power as long as the end user is in the required voltage range, but it will internally shunt power and disconnect itself from the bus if the voltage range is exceeded. Shunt resistors sized for maximum output power of the convertors are mounted on the test stand for this purpose. The bus is connected to a capacitor bank for transient energy storage that allows a range of 10000 to $100000 \mu \mathrm{F}$.

Safety systems on the test racks are implemented through the DAQ system and through hard-wired circuitry. The user may specify upper and lower bounds for any parameter monitored by the DAQ system. The DAQ software will safely shut down operation of the test article when an out-of-bound condition is sensed. Parameters that trigger the shutdown of the ASC-L include low or high hot-end temperatures, low or high rejection temperatures, high PV temperature, high piston amplitude, and loss of building power. If a shutdown is initiated, the DAQ software commands the hot-end temperature to $10^{\circ} \mathrm{C}$ and the circulator temperature to $25^{\circ} \mathrm{C}$, and it turns off the heater power supplies. The convertors continue to be motored with the SCC until the average hot-end temperature reaches $700^{\circ} \mathrm{C}$, with the nominal hot-end 
temperature being $850^{\circ} \mathrm{C}$. A shutdown is initiated for loss of building power after 5 min of operating on an uninterruptible power supply (UPS) system. Another safety feature in the software notifies the end user when a shutdown occurs, logs the fault via the DAQ, and records the data. The end user is notified by a cell phone text message that indicates the fault code of the shutdown.

Two hard-wired protection devices installed in the operations rack function independently of the software-based protection: temperature limit and failsafe protection circuit (FPC). If a fault is registered by the temperature limit device, the DAQ, or an optional third source, the heater power supplies are disabled and a fault is indicated by a light-emitting diode (LED). If the hot-end temperature of either convertor exceeds the user-defined limit, the limit controller removes the heater power from both convertors via a relay. A FPC was implemented to prevent piston overstroke. The FPC can monitor up to four input signals. Each input has an associated, user-adjustable setpoint. When any signal exceeds its setpoint, the convertor controller is disconnected, and an emergency load is applied across the alternator and a signal is sent to the DAQ software. A protection circuit interface panel provides a means for the user to be notified via LEDs when a piston amplitude limit is exceeded. The user can reset the protection circuit after the fault and can manually stall the convertors by flipping a switch on this panel. The user also can disconnect the protection circuit and select between AC bus power supply control and the SCC.

The SRPS has been in extended operation since May 2013. To date, no noticeable changes have been identified in system performance. The system performance data, as shown in Figure 17 and Figure 18, is changing with the ambient temperature in the SRL. The temperature regulation in the laboratory is not controlled as desired so ambient temperature changes are common. The figures also indicate a loss in data collection for approximately 1 day due to a computer malfunction. The system performance data will continue to be analyzed for thousands of hours. Any noticeable changes in performance will be identified and if possible corrected.

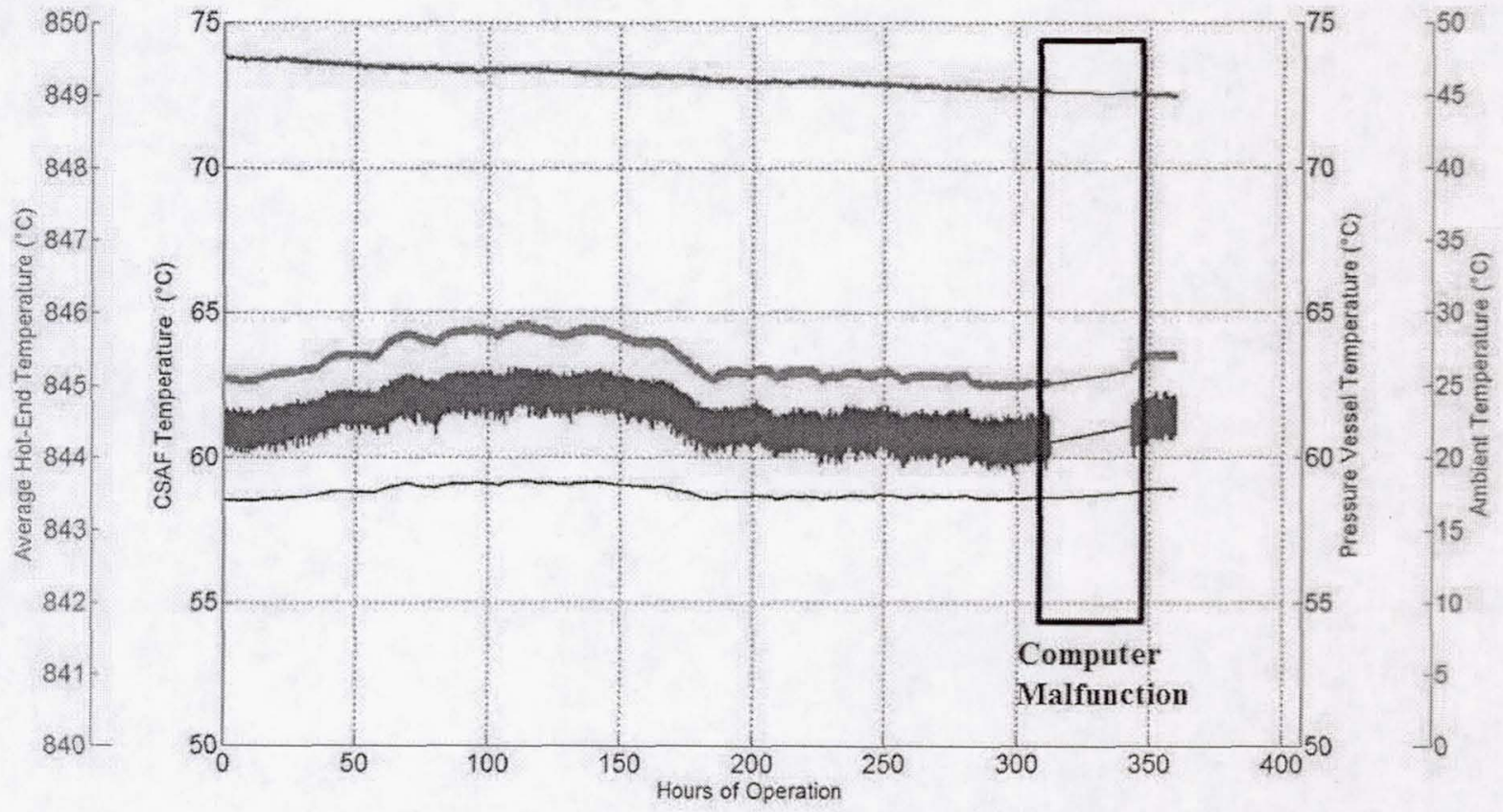

Figure 17.-ASC-L temperature performance data. 


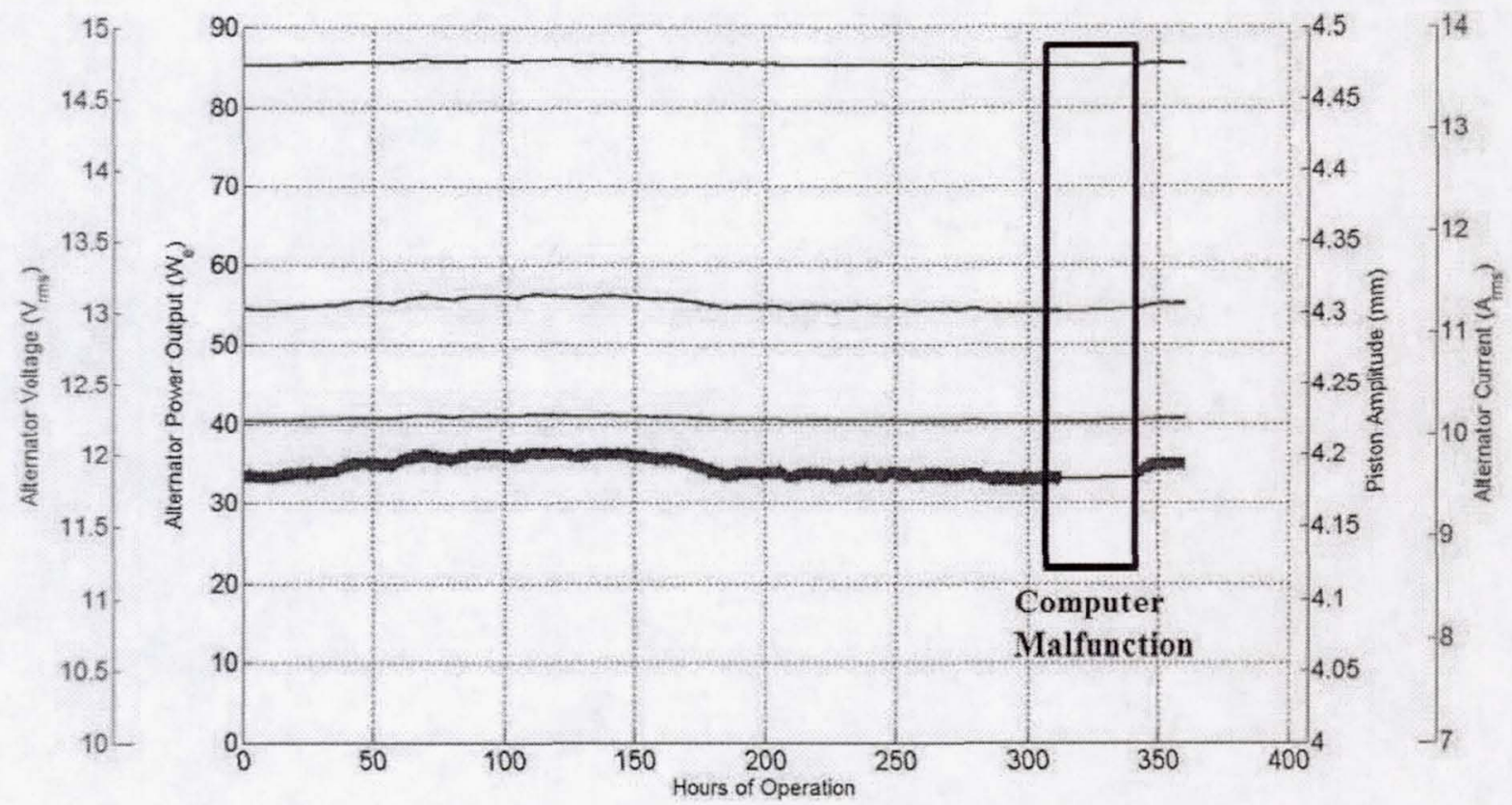

Figure 18._ASC-L alternator and piston amplitude performance data.

\subsection{Discussion}

The testing described in this paper sought to reduce the risks associated with developing a small radioisotope power source for space (primarily lunar surface) applications based on using a single Stirling convertor.

Magnetic and electric field measurements of the ASC-L were similar to the baseline ASC-E2. Field levels were not significantly different when the ASC-L was controlled with the SCC or a simple AC-bustype controller.

Fault tolerance of the SCC was extensively exercised. A wide range of spacecraft and ASC faults were introduced while operating at full power level. In addition, many different faults were also injected internal to the controller. In all cases, the fault was detected, a corrective action taken, and telemetry updated with diagnostic information on the event and response. ASC piston amplitude was controlled during all these fault cases. While piston amplitude had transient changes during some fault responses, careful design of the fault detection and response algorithms meant the piston never hit the hard stop even when switching controller boards.

External disturbances such as vibration during launch affect motion of the ASC case. The alternator magnet is directly connected to the convertor piston while the alternator coil is part of the external case. Hence, external disturbances result in ASC current output disturbances as the coil is moved relative to the magnet. Vibration testing at flight levels showed that current variations approached the limits of the controller's full digitization range. Exceeding that range would cause the control algorithm to process inaccurate input current values and therefore, risk loss of control. To allow higher external vibration levels, the SCC input alternator current dynamic range should be increased. However, if dynamic range is increased, resolution will be decreased and ASC output power level noise may degrade. Hence, an analysis to predict maximum input current while under external vibration should also be performed to support optimizing the dynamic range/noise tradeoff.

Conducted emissions testing of the SCC showed a large current component at twice the ASC operating frequency. The current is caused by the controller's full wave rectification of the ASC output power. For a capacitive bus-based electrical power system, the bus capacitance would smooth the current and minimize emissions. A battery-based power system would also reduce emissions but in that case the 
ripple current would also be equivalent to charge/discharge cycles at a high frequency. The impact on battery life of such treatment is unknown so design work to add an additional output regulator stage to remove most ripple current has started. Simulations of that preliminary design show that it should be possible to lower output current ripple below a few $10 \mathrm{~s}$ of $\mathrm{mA}$ at the expense of additional power loss in the controller.

Open loop testing of the ASC-L passive balancer showed a force reduction between the convertor and spacecraft of somewhat more than a factor of 2 . However, the passive balancer is only helpful over a fairly narrow ambient temperature range. Conceptually, a control algorithm may be possible that senses force (or related parameter) between the convertor and then changes operating conditions, such as piston oscillation frequency, to maintain the effectiveness of the passive balancer over a wider temperature range. The ASRG reduces force far more than the passive balancer by using a second ASC with all internal masses moving in the opposite direction to the first ASC so the net momentum across both convertors is cancelled to the extent that ASC characteristics are matched. Conceptually, for a single ASC-based power source, an actively driven balance mass could be used to similarly cancel convertor momentum. The active balancer would require power to drive its balance mass as well as control electronics to match ASC motion. Hence, less power will be available for the load but that may be an acceptable trade for some applications.

The test results we have presented here show that is feasible to develop an SRPS suitable for a small lunar-lander- based seismometer network. The largest remaining challenge is developing a mechanical interface between the SRPS and lander that does not allow vibration from the SRPS to affect the quality of collected science data. Controller improvements to reduce current ripple, tolerate launch vibration, and balancer effectiveness would also be helpful.

\subsection{Conclusion}

The Small Radioisotope Power System (SRPS) is compatible with lunar missions that require a single Advanced Stirling Convertor (ASC) and have a low vibration requirement due to instrumentation. The SRPS has the potential to be adapted for other planetary missions as well. The project resulted in delivery of a Lunar-Derived Advanced Stirling Convertor (ASC-L) with passive balancer, simulated lunar lander test stand, and Single Convertor Controller (SCC). Component- and system-level testing of these items has been completed with plans to continue extended operation in order to gain long-term system data. The project produced a low mass and volume, high efficiency, and reliable SCC. The project can be adapted for other missions that require even less vibration than that of an ASC with passive balancer through use of an active balancer. Initial analysis shows that an active balancer can potentially decrease vibration levels beyond that of a passive balancer.

\section{References}

1. Dugala, G.M., et al.: Small Radioisotope Power System at NASA Glenn Research Center. Presented at the 9th International Energy Conversion Engineering Conference, San Diego, CA, 2011.

2. Dugala, G.M.: Test Rack Development for Extended Operation of Advanced Stirling Convertors at NASA Glenn Research Center. Presented at the 7th International Energy Conversion Engineering Conference, Denver, CO, 2009. 




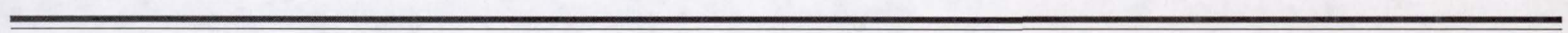

